\title{
Developments in integration of advanced monitoring systems
}

\author{
Przemyslaw Oborski
}

Received: 12 December 2013 / Accepted: 30 June 2014 / Published online: 26 August 2014

(C) The Author(s) 2014. This article is published with open access at Springerlink.com

\begin{abstract}
Monitoring is an important part of manufacturing process control and management. It plays a crucial role in ensuring agility in a manufacturing system, process robustness, responsiveness to client demands, and achievement of a sustainable production environment. Recent developments in information systems and computer technology allows for the implementation of new philosophies that integrate various monitoring applications into one complex system connected through company-wide IT systems and with systems operating throughout the whole supply chain. This paper reviews developments in the area of advanced monitoring and integration. Research on new approaches, standards, developed solutions, and company applications are presented. New directions of research and development in all areas of advanced monitoring and implementation of recent IT solutions are discussed.
\end{abstract}

Keywords Advancedmonitoring · Supervision · Integration · Manufacturing $\cdot$ Computer integrated production $\cdot$ IT systems $\cdot$ Cloud manufacturing $\cdot$ SCADA $\cdot$ Multi-agent systems $\cdot$ Review $\cdot$ Development

\section{Introduction}

Manufacturing companies competing in the global market are forced to continually maintain manufacturing quality and products improvement. Additionally, at the same time, it is necessary to also reduce prices and shorten production times. These considerations have become even more important since the financial crisis of 2008 [1]. Meanwhile, product

P. Oborski $(\bowtie)$

Warsaw University of Technology, ul. Narbutta 86, 02-524 Warsaw, Poland

e-mail: p.oborski@op.pl complexity is rapidly increasing and new hard-tomanufacture materials are being continually developed. There is growing sophistication in production processes along with technical risks [2]. Today's product development process, production environment, and equipment must perform at levels that seemed impossible just a few years ago [3]. The expectations of customers for increased safety, product quality, availability and agility, together with the need to meet governmental, business, and social requirements elevate the speed and pressure on manufacturers to manage their assets more effectively [4]. The necessity to maintain — and very often increase-operational effectiveness whilst simultaneously reducing capital and operating expenditures is an ongoing challenge for manufacturing enterprises [5]. To address these demands, a significant change is necessary from past culture, processes, management and organisational concepts [6].

Strict cooperation of companies with various competencies and production resources is necessary especially in the case of small and medium enterprises [7]. At the same time, business risk is growing rapidly and needs to be better addressed. Legal and financial responsibility for defective products or poor quality has never been higher. Ineffective businesses have to close or move to lower cost countries [8]. Such factors are forcing manufacturing companies towards a more rapid development of production systems [9]. Some of the most important changes are coming from the area of integration of information flow through sophisticated IT solutions and connection with advanced monitoring and supervision systems [10]. This has become especially important in an age of rapidly developing Internet-based applications, cloud computing, etc., which allows for the integration of company systems into the supply chain in one system that can even include integration of shop floor control [11].

Looking directly at the production shop floor, we can see that there are a number of ideas that have been developed for 
manufacturing systems organisation, including agile [12], holonic [13], fractal [14], and others. All are based on the common concept of a distributed and dynamic shop floor, where autonomous assets interact to overcome disturbances and problems during order performance. In this kind of system, it is clear that monitoring plays a fundamental role in supporting the operation of particular machines, process, and supervision of manufactured parts [15]. Such autonomous monitoring of assets has to be integrated into one flexible, open, and robust system that allows for a sustainable production environment. The development of integrated monitoring and supervision systems is also important from the so-called green manufacturing, a new research area that focuses on the reduction of energy consumption [16, 17].

The aim of this article is to present a review of new approaches to integration of monitoring and supervision functions into one system connected with machine control, shop floor control, company IT systems, and with other company systems in the supply chain.

\section{State-of-the-art: overview}

Most research in the field of monitoring is focused on standalone solutions that are not connected in one complex system as shown in a review by Byrne et al. [18] and Teti et al. [19]. New developments in computer technology and data processing, new standards, solutions and advances in programming technology create new opportunities for the integration of monitoring systems. The costs for monitoring implementation is decreasing because of miniaturisation, multifunctional sensors, micro-electro-mechanical systems (MEMS) application, embedded intelligent solutions development, implementation of new data processing standards and lower data-processing equipment prices. With these factors in mind, the potential for development of integrated advanced monitoring systems is very high. Rapid development of IT systems [20], new solutions like cloud computing [21,22], and multiagent applications [23] allow currently for the practical implementation of monitoring integration into one distributed system.

There is also a growing need for integrated advanced monitoring systems that can support production and supply chain management, optimisation of production processes, and for advanced control systems that would allow for the evaluation of product quality based on an analysis of monitored manufacturing parameters. As such, real breakthroughs in the philosophy of monitoring systems development and application seem practical and highly likely.

A detailed review of the state of the art in this area and related technologies that are necessary for integrated monitoring systems development are presented and analysed in the paper. Expected research directions are also presented and discussed. Developments in monitoring and supervision systems are analysed in Section 3, which also contains an overview of state of the art in the main areas of monitoring systems application, such as condition monitoring systems (Section 3.1), shop floor monitoring (Section 3.2), monitoring in maintenance systems (Section 3.3), and integration of monitoring with control functions (Section 3.4). Next, Section 4 provides a concise review of the latest advances in research on condition monitoring systems-development of condition monitoring and supervision systems. Finally, Section 5 provides a comprehensive state-of-the-art review with detailed analysis about necessary and possible research and development directions in the integration of monitoring into a coherent system-developments in integration of monitoring systems.

This main part of the paper is divided into the particular spheres necessary to build an integrated monitoring system. The following subsections focus on: general direction of development (Section 5.1), development in technical areas of monitoring integration (Section 5.2) containing sensors, computer numerical control (CNC) controllers, real-time systems, and embedded systems analysis. The next subsection is on new approaches in systems areas of monitoring integration (Section 5.3) and includes the MTConnect standard and cloud computing. The last subsection is an overview of software solutions for integration of monitoring systems (Section 5.4). Integration based on a client-server architecture, solutions based on supervisory control and data acquisition (SCADA) systems, and multi-agent technology is comprehensively analysed. Special stress is place on multi-agent systems and their major challenges that have not yet been well addressed in research, but give number of advantages important for manufacturing IT systems.

\section{Monitoring and supervision systems}

\subsection{Condition monitoring systems}

The ability to meet increasing customer expectations will require more common implementation of monitoring and supervision functions into machining processes and machine tools. Such functions will have to be integrated with shop floor control and companywide IT systems operating at the management level [24]. Research are carried out on integration of tool and machine condition monitoring with $\mathrm{CNC}$ control by allowing access to internal signals in the numerical controller, such as motor power, motor current, or additional measured signals like, vibrations, position, etc. [25]. Research has also looked into integration of various monitoring functions in one system.

Currently, however, most monitoring devices are implemented as local, stand-alone solutions [19]. In the near future, in order to meet client requirements, monitoring will have to allow for ongoing supervision of the machining process, 
machine, and produced part parameters. The collected information will be used for production process online control. Further, this production history will need to be archived as a history of the particular workpiece. The effective implementation of complex monitoring and supervision systems raises some significant challenges. One of the most important is obtaining timely, reliable information on the state and conditions of the manufacturing process and machine tool. Another is to analyse the obtained data in order to diagnose a problem [26] (Fig. 1).

Then, based on the diagnostic information, the decision on a possible action should be performed automatically or by the operator. In addition, information about the process and machine tools, detected problems, decisions, and control activities carried out should be archived in the form of an order history. This history shall include comprehensive information about all aspects of the part and machining. This should allow an analysis of any causes of malfunctions occurring during operation of the product, or potential faults that can result from the manufacturing process. This is particularly important in the manufacture of vital and expensive parts, such as in the aviation industry or energy field. For example, in 1997, the AIA report on Rotor Integrity Sub-Committee stated that approximately $25 \%$ of the faults in air engines are caused by irregularities in the manufacturing process [19]. This approach will be increasingly important with the constantly progressive development of machining processes, processing and analysis of data, and the growing complexity of products, Moreover, in the future, this approach will also be increasingly important for less complex manufactured products in other industries.

\subsection{Shop floor monitoring}

Monitoring and supervision functions should be a part of sophisticated information systems. Such systems should allow for control of all aspects of the production system, including machine tool operation, production process, manufactured product, and performed orders [27]. The system has to monitor parameters that are important for proper operation of machine tools, production process, etc. Finally, the system should facilitate decisions that address discovered problems, avoids losses, or reduce risk. Decisions can be taken automatically or by operator that is supported by the IT system (Table 1).
A significant problem in process, workpiece, and machine tool condition monitoring is the large number of highly variable parameters. A high sampling frequency is dictated by high-speed tool or workpiece rotation, movement of machine elements, etc. [28]. To manage this problem, data has to be collected locally and analysed by dedicated algorithms to select important information. Such information can then be used for further action. The following table presents examples of parameters that can be monitored in a manufacturing system and decisions that can be taken to solve discovered problems (Table 2).

The parameters provided above concern one machine, the process performed on it, and on one workpiece. A manufacturing system, however, consists of a number of cooperating machines. Each machine can be of a different type, performing different processes, and use a number of various tools. Similarly, there are a wide variety of manufactured parts that can be produced by different processes using various machines.

Information obtained from analysis of collected data should be used in the next step to take control decisions that will result in a particular action to solve a discovered problem. A decision-taking action is usually not a standard action. Sophisticated algorithms based on artificial intelligence or examination of databases with suggested solutions are very often required. This may involve performing negotiations between interested objects, machines, modules, etc. This can be especially important for changes to the manufacturing process or production schedule.

The actions proposed in the above table should be taken locally as the result of a locally performed decision process. The decentralisation of the decision process is necessary to increase system efficiency, stability, and resistance to disturbances [24]. This has to support flexibility in the system and an openness to configuration changes [29]. The centralisation of control decisions was one of the main problems of past flexible manufacturing systems and one of the main reasons behind their limited implementation [30].

\subsection{Monitoring in maintenance systems}

An important part of a monitoring application is the maintenance systems. Current manufacturing systems have to work
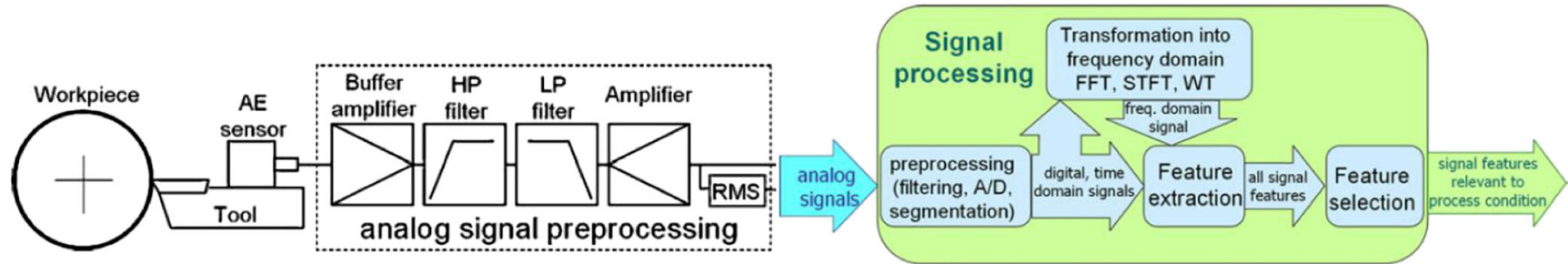

Fig. 1 An example of signal processing in a monitoring system (based on Teti et al. [19]) 
Table 1 General requirements of a shop floor level monitoring system

\begin{tabular}{|c|c|}
\hline Requirements & Characteristics \\
\hline Data acquisition & Data acquisition from monitored process and machines. \\
\hline $\begin{array}{l}\text { Monitoring of manufacturing } \\
\text { process, machines, and parts }\end{array}$ & $\begin{array}{l}\text { Analysis of data from manufacturing process and combining this with set values. Discovery of } \\
\text { problems. Taking control decisions, if necessary, when deviations are detected. }\end{array}$ \\
\hline Processes control support & $\begin{array}{l}\text { Support for taking and performing control decisions aimed at realising production plan and } \\
\text { disturbance elimination. }\end{array}$ \\
\hline Data archiving & Registration and archiving data from machine, process and part monitoring. \\
\hline Easy change of configuration & $\begin{array}{l}\text { Easy reconfiguration of the system (changing functionality, adding new machines, } \\
\text { changing system structure, etc.) for reconfiguration of the manufacturing system. }\end{array}$ \\
\hline Flexibility & $\begin{array}{l}\text { Flexibility in meeting different orders, also orders that need functionality not } \\
\text { supervised during system development and that have to be added. }\end{array}$ \\
\hline Resistance to disturbances & $\begin{array}{l}\text { System stability and resistance to disturbance, ability to take local decisions to } \\
\text { eliminate influence of disturbance on system performance. }\end{array}$ \\
\hline Easy to use & User-friendly system with intuitive decision support, easy to reconfigure and add new functionality. \\
\hline Operating in distributed environment & $\begin{array}{l}\text { Operating in distributed environment consisting of computers, controllers, mobile terminals, } \\
\text { and equipment connected by various kinds of computer networks. }\end{array}$ \\
\hline Independence in computer operating system & Ability to operate with various control equipment and on various computer operating systems. \\
\hline
\end{tabular}

with zero breakdowns. The reliability of the production system is of crucial significance during cooperation in the supply chain, that, nowadays, usually works in a just-in-time environment, without stores, and without reserves [31] (Fig. 2).

One of the important driving forces pushing forward research on development of monitoring systems was the necessity to deliver information about the status of a machine and processes in maintenance systems [32]. Currently, using a reliability maintenance approach needs advanced monitoring systems that have to deliver predictable information about possible problems, lower functionality, or breakdowns that can appear in the near future [33]. Such an approach requires complex integrated monitoring systems that analyse online all crucial machine and process parameters. The idea of Emaintenance thus developed with the emergence of the Internet and cloud computing [34]. This concept is based on

Table 2 Examples of parameters that can be monitored in manufacturing system and decisions that can be taken to solve discovered problems

\begin{tabular}{|c|c|c|}
\hline Monitored object & Examples of parameters that can be monitored & $\begin{array}{l}\text { Examples of decisions that can be taken to solve } \\
\text { discovered problems }\end{array}$ \\
\hline Machine tool & $\begin{array}{l}\text { - Machine tool or critical components condition monitoring } \\
\text { - Thermal errors, geometric and dynamic parameters } \\
\text { - Vibrations, temperature, acoustic emission } \\
\text { - Proper operation of mechanisms } \\
\text { - Maintenance activities } \\
\text { - Time of work (preparation, processing, breakdown, } \\
\text { maintenance) }\end{array}$ & $\begin{array}{l}\text { - Compensation of dimension and geometry changes } \\
\text { caused by temperature changes or process forces. } \\
\text { - Changes in process parameters, eg., to avoid vibrations or } \\
\text { increase temperature. } \\
\text { - Starting of maintenance activities. } \\
\text { - Testing to analyse discovered problem or to check proper } \\
\text { operation after maintenance. } \\
\text { - Emergency stop, eg., in machine breakdown. } \\
\text { - Working with limited functionality. } \\
\text { - Proposing action plan to solve the problem. }\end{array}$ \\
\hline Machining process & $\begin{array}{l}\text { - Tool condition monitoring } \\
\text { - Temperature, vibrations, acoustic emission } \\
\text { - Process efficiency } \\
\text { - Process parameters }\end{array}$ & $\begin{array}{l}\text { - Process optimisation - process parameters changes. } \\
\text { - Changes in process parameters, eg., to avoid discovered } \\
\text { problems or minimise loses. } \\
\text { - Support operator by suggestion of optimal parameters } \\
\text { suited to actual process condition. } \\
\text { - Emergency stop, eg., in the case of tool breakdown. } \\
\text { - Proposing action plan to solve the problem. }\end{array}$ \\
\hline Workpiece & $\begin{array}{l}\text { - Geometry (dimensions, tolerances) } \\
\text { - Surface parameters (roughness, quality, } \\
\text { geometric parameters) } \\
\text { - Material parameters (temperature, hardness, stress) } \\
\text { - Manufacturing data: time (preparation, processing, waiting), } \\
\text { machine and tool(s) number(s), operator, etc. }\end{array}$ & $\begin{array}{l}\text { - Selection of optimal process parameters. } \\
\text { - Recording history of manufacturing: machines, tools, parameters. } \\
\text { - On-line optimisation of process parameters according to } \\
\text { measured part parameters. } \\
\text { - Optimisation of production parameters - time, schedule, } \\
\text { batch size, etc. } \\
\text { - Proposing action plan to solve the problem. }\end{array}$ \\
\hline
\end{tabular}




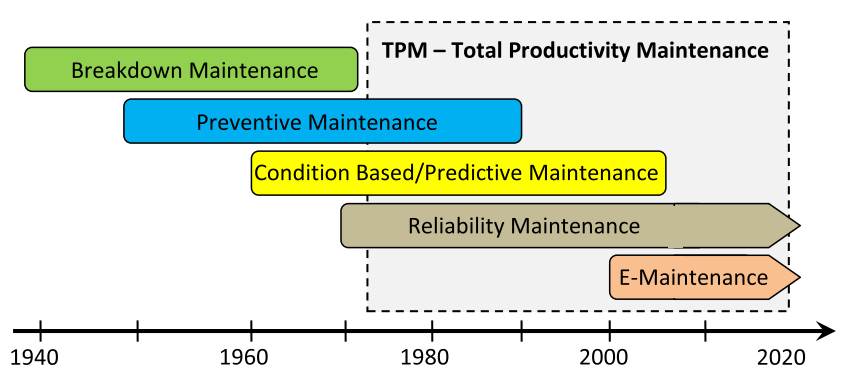

Fig. 2 Development of maintenance systems

maintenance systems that manage and exchange monitoring information/data via the Internet. The development of E-maintenance will force integration of monitoring and supervision into one complex distributed system operating over an entire shop floor or even throughout the whole supply chain $[35,36]$. Research shows, however, that current IT-based maintenance systems have not been implemented yet to any large extent by manufacturing companies. Such systems are still considered in most cases as an additional cost, not as a business opportunity. Maintenance systems usually are only implemented when companies understand that proper maintenance allows for systems and process optimization, and not only problem prevention [37].

The situation is different in the process and power industry, which tends to be dispersed over large areas and production devices very often operate automatically without operator supervision. In this kind of business, remotely operated maintenance systems are necessary (Fig. 3).

Monitoring in the process industry is usually based on SCADA systems. They allow for data acquisition directly from sensors or PLC that control various parts of the production devices. The concept of remote monitoring and maintenance based on the idea of E-maintenance was first introduced by Lee [38]. It is helpful to the development of integrated monitoring for manufacturing, although it was developed mainly for maintenance systems in the process industry. The author proposed six functional requirements:

1. Multi-sensor integrated monitoring and control system: integration into one system, a number of sensors and local control devices responsible for operation control of various production devices.

2. Communication: integration of geographically dispersed machines through computer networks.

3. Data abstraction: only relevant data are to be transmitted through the network.

4. Knowledge acquisition and learning: there is a need for intelligent tools to acquire and organise data on the manufacturing processes at one site to share it with other sites. The whole system should be capable of learning the behaviour of users at different sites.

5. Natural language translation: tools to automatically translate text into other languages.

6. Telemaintenance and diagnostics: to facilitate work by technical personnel to perform diagnostics on machines that are geographically distributed.

Based on these requirements, a framework for web-enabled e-maintenance systems was proposed [39]. Ever since the emergence of a number of remotely integrated maintenance systems, some have used intelligent agents and multi-agent technology [40-44]. An example of such a system is the intelligent control-maintenance-management system (ICMMS) based on a multi-agent concept. The aim was to apply it to monitor the equipment of an automation system of a hydroelectric generating unit [45]. An interesting solution is a condition monitoring multi-agent system (COMMAS) that was developed and applied to monitor a gas turbine start-up sequence [46]. A relevant review of the integrated maintenance systems developed mainly for process, chemical, and power industry has been done by Campos [24].
Fig. 3 Integration of emaintenance, e-manufacturing, and e-business systems [34]

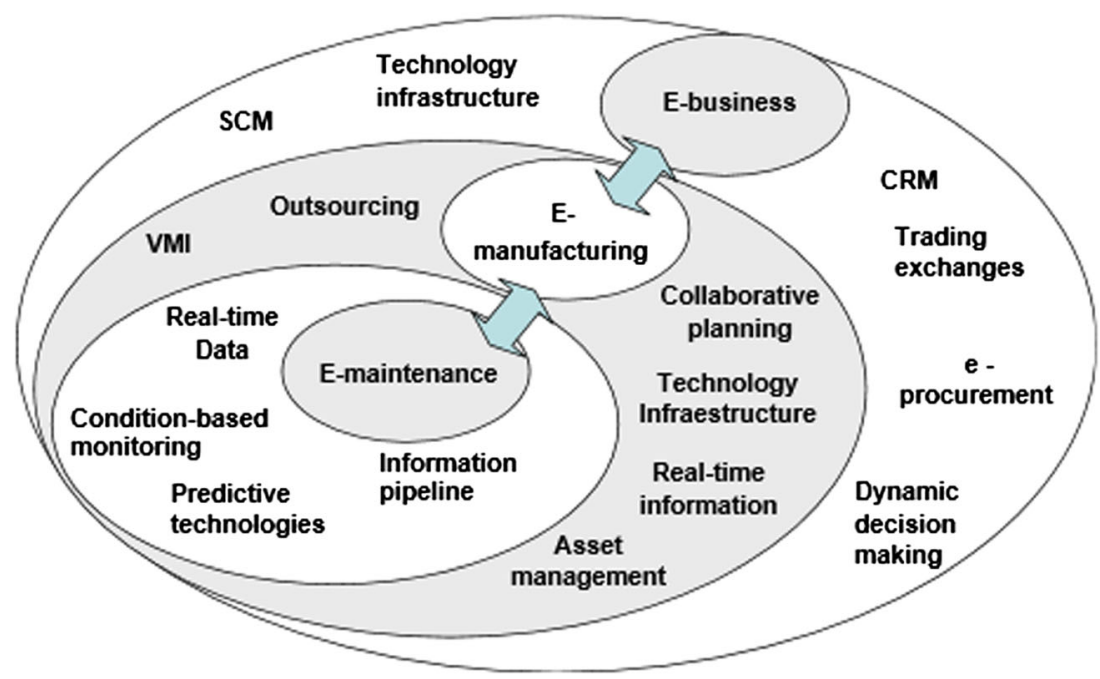




\subsection{Integration of monitoring with control functions}

Advanced monitoring and supervision system for manufacturing processes should integrate a number of sophisticated functions starting from data collection, through analysis, and until decision taking to identify problems and propose necessary action. Usually, a system only plays an information role for an operator working with a particular process. A system gives information about a problem to an operator who has to then take a decision and execute an appropriate action [19]. However, to meet the requirements of advanced manufacturing, a monitoring system have to be integrated with companywide IT systems and should be connected with control functions that allow for taking of actions according to identified problems [6]. The functions integrated in the frame of an advanced monitoring and supervision system can be presented as a process (Fig. 4). This process starts with a collection of data by sensors, continues through problem detection, and engages until presentation of information about a detected problem for the case of a monitoring system. If control functions are added, the response to the detected problem is the decision about an action and finally an action that is performed to solve the problem. The main functions of a monitoring and supervision system model are presented next.

\subsubsection{Signal acquisition}

Signal acquisition is usually done through specialised cards that collect sampled data from sensors in real time. Sensors are dedicated to taking data from a particular part of a process, machine element, or part of a measurement device. Collected data has to be roughly prepared and then filtered and analysed to take from the signals any information that is necessary for further analysis. This is difficult due to typical high frequencies in probing and the large number of disruptions caused by a machining process and machine tool operation.

\subsubsection{Detection}

Detection is an important and difficult part of monitoring. Its aim is to analyse data collected from sensors to determine if there are any abnormal signals that can inform about a problem in the monitored process, part of a machine, or product. Special intelligent algorithms should be used to allow efficient and correct detection of changes in monitored data. This should allow for detection of changes that inform about present and possible future problems.
Fig. 4 Model of advanced monitoring and supervision system connected with control functions

\section{MONITORING FUNCTIONS}

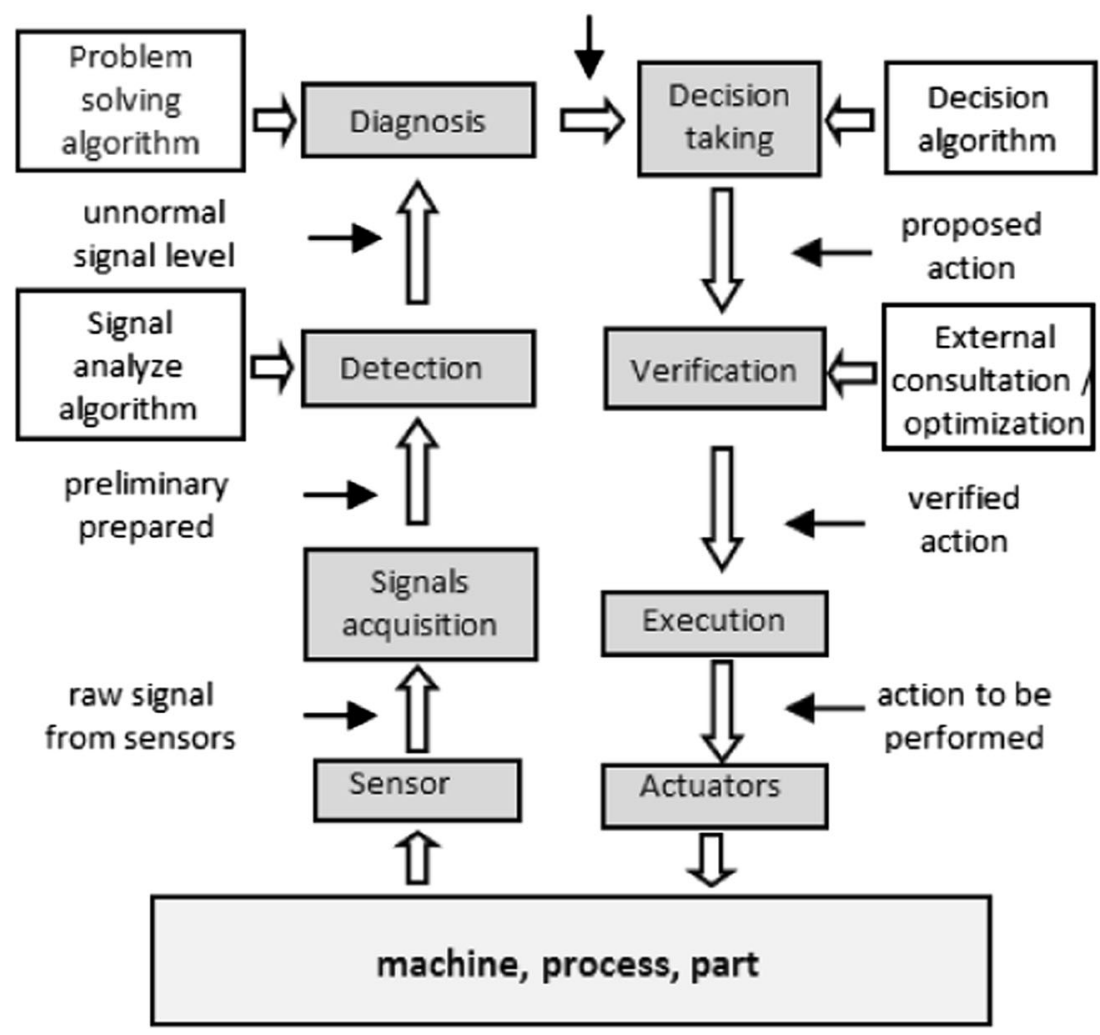




\subsubsection{Diagnosis}

The aim of diagnosis is to clearly determine the problem that has occurred in a particular machine process or manufactured part. This requires the use of a dedicated algorithm that can be based on artificial intelligence or a knowledge base that allows for problem solving. Information about a detected problem can then be presented to operator or a control action can be performed.

\subsubsection{Decision taking}

The decision-taking module is part of control functionality. It should be responsible for preparing the most optimal action that reacts to a detected problem. It has to be based on an advanced decision-taking algorithm. The proposed action can be verified by external consultation with either a software coordinator or by a machine operator.

\subsubsection{Execution}

The execution of a control action is the last activity in the process of monitoring and control. This is aimed at performing an action that eliminates the problem or reason for the problem detected by the monitoring system.

\section{Development of condition monitoring and supervision systems}

The rapid development of methods, tools, monitoring and supervision systems, combined with sensors and computing technique improvement allows for more efficient acquisition of information about processes, machines, and parts [47]. The entire spectrum of processing and data analysis methods is based on both direct and indirect measurement. Parameters such as forces [48, 49], load drives [50], current [51], cutting forces [52], torques [53], temperature [54-56], acoustic emission [57], sound signals [51], noise and surface acoustic wave [58], vibrations [59, 60], or vision [61, 62] are used for this purpose. Data acquisition uses various kinds of sensors: mechanical, piezoelectric, optical, laser, etc. [63]. Research is moving towards wide implementation of sensors based on microtechnology embedded in machine parts, drivers, chucks, tolls, and machined parts. Examples of such approaches can be found in [64] and [65]. Such a solution connected with special control devices is called intelligent devices. Some physical phenomena are also used for acquisition of necessary data [66]. These devices allow for the development of sensorless applications [67-69].

Obtained data needs to be subjected to advanced processing and analysis methods using multilayer neural network- based algorithms, fuzzy logic, and analysis in the field of time and frequency [70]. A monitoring system can increase reliability and robustness in terms of managing disturbances, and is usually based on data from several independently measured sources. Some examples include a cutting force, torque, acoustic noises, and vibration. One of the key problems lies in achieving advanced data processing of the obtained signals. It has to allow for the extraction of relevant information useful for further analysis. As a result of analysis, signals that carry information have to be separated [71]. Such information can be compared with an analytical model of the machine, workpiece, or manufacturing process [72]. Additionally, models based on artificial intelligence can be used for this purpose [73]. Based on advanced algorithms, the current state of a process is specified and predictions are made about future behaviour [63].

A literature review shows that most research focuses on monitoring of the following areas:

- Tools and tool holders: operating conditions - tool wear and tool breakage, geometry, temperature, vibrations [74-79], and also for micro milling [80-82]

- Chipset: chips formation, chip breaking, and chip removal [83-87]

- Machining process: disturbances, errors, variables, process status, and parameters [64, 88-93]

- Manufacturing part: surface of the part, surface roughness, surface condition, and parameters [94-101]

- Machine: the machine status, drives wear, spindle bearings damage, total preventive maintenance (TPM), work condition (vibrations, temperature, and machine distortions) [102-106].

A comprehensive overview of research and solutions was done by a CIRP working group in 2010 [19]. To what was mentioned, it is necessary to add monitoring for manufacturing parts geometry and quality. Examples of research in this area can be found in the following papers [101, 107-109]. An interesting area of research is assessment of the machinability of hard-to-machine materials supported by process monitoring [110]. The so-called green manufacturing also offers a new research area aimed at reducing energy consumption. An example comes from the development of automated monitoring of machine tool energy usage in correlation with the operations being performed [111].

Based on monitoring data, adaptive control systems [112] and optimisation systems [113] can be developed. Monitoring and supervision systems often have modules supporting decision-making. Those modules usually are based on neural networks [114-116], genetic algorithms [117], fuzzy logic [118], or knowledge and expert systems [119]. They allow for automatic decision taking on the basis of analysed signals changes or support of the operator through suggestions about 
an optimal decision. Another important area of research is focused on the social aspects of monitoring systems that have to cooperate properly with machine operators [120-122].

Tool and machine-condition monitoring systems are becoming increasingly advanced. There are industrial applications, particularly in the case of mass- and large-series production with stable machining parameters. However, the increasing demands on the quality of manufactured products, reliability of the production systems and processes, and the need to reduce costs is pushing towards the monitoring of selected areas of the manufacturing process by dedicated, advanced supervision systems. Manufacturing companies are increasingly interested in not only the monitoring of one or two areas, but in having a complex, holistic approach to overall manufacturing supervision.

\section{Development in integration of monitoring systems}

\subsection{General direction of development}

A significant problem in manufacturing systems is the challenge of providing effective monitoring of a large number of highly variable parameters. Control of these parameters and adequate reaction to improper values changes is necessary to maintain a high efficiency in machine tools, production processes, and product quality. This is now critically important for effective management of production process, manufacturing systems, and the product production process [123].

Another key area of concern is management of the complex history of a manufactured part. Such a history should consist of information from the monitoring of the machining process, along with machine status and workpiece parameters. It is very important to integrate monitoring with other company IT systems, like the CAM, shop floor control, maintenance, and management systems [10]. From a global point of view, the development of manufacturing systems is moving in the direction of large, distributed, flexible virtual organisations focused around supply chains that are connected by IT systems that allow for full integration of the information flow [20, 124].

In such approaches, integrated monitoring and supervision systems connected to supply chain-wide IT systems will play a crucial role. The integration of machining process monitoring and supervision requires a connection into one system of various applications, which are currently developed independently by individual research teams. A comprehensive, holistic approach to the problem of monitoring would have several advantages. This integration would allow for comprehensive monitoring of all relevant parameters: process, tool, machine, and workpiece.

The data collected and processed by multilevel analysis would allow for a holistic picture of manufacturing process and the history of the product formation. This would also provide a synergy effect, where the results of the measurement of some parameters and areas would provide for more relevant inference in other areas. For example, detecting changes in the cutting forces, machine vibration, and changes in a workpiece surface would allow one to learn about both the cause of a phenomenon and also the final impact on product quality. This knowledge would open up the potential for identifying the causes of a problem, its elimination, and proper treatment towards a final product (Fig. 5).

An integral part of the supervision systems are sensors. Similarly to data processing and decision-making, they should be integrated into one system. Such an approach should allow for cost optimisation and simplify data acquisition. The sensors should allow for modular construction of the system, based on a common architecture for the interchange of data. This would make it possible to implement various items, such as sensors, equipment, and applications for data acquisition and signals processing. Such systems should also allow for easy integration with machine control systems, in order to allow control data acquisition and implementation of the control functions. The integration of monitoring and supervision systems potentially gives the ability to reduce cost, through the use of common solutions that could be standardised. Some parts could be installed and offered by machine tool producers. The need to implement the integration of monitoring into one system is not only logical from a theoretical point of view, it also meets business expectations and industrial companies that are beginning to look for complex solutions that are currently not available [126].

\subsection{Development in technical areas of monitoring integration}

Although researchers have sounded the alert for the importance of integration of monitoring functions into one system [127], most current applications for manufacturing systems are dedicated to supervising changes of only a few selected parameters [19]. Good examples of such systems are monitoring of a tool condition system [80] or machine temperature monitoring based on compensation of thermal deformations [128]. The following sections discuss the most important components in monitoring systems integration.

\subsubsection{Sensors}

Sensors that are an integral part of the monitoring system are also some of the most expensive and difficult to implement devices. A significant problem is implementation of sensors in a location to generate an appropriate signal, such as at the end of a cutter. It is especially difficult when several sensors have to be installed [129]. It is also important to consider the role of communication between sensors implemented in machine 
Fig. 5 Web-based integration of maintenance/monitoring system concept [125]

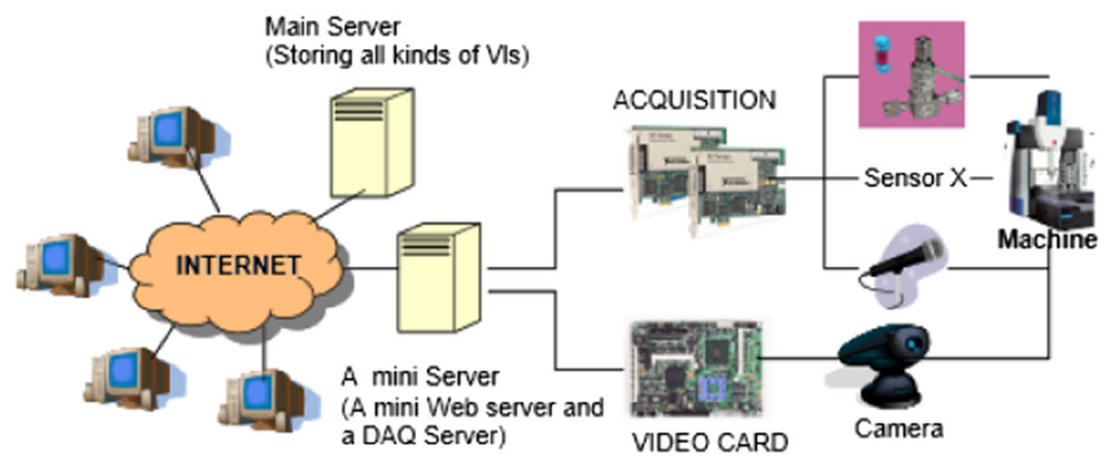

elements, tools, and workpieces and from the other side in monitoring systems and machine controllers [130-132].

Currently, there are modular solutions that are commercially available $[129,133]$. Using these systems, it is possible to build easy-to-reconfigure measurement chains or even ready-to-use solutions suited to particular machining processes [134]. Research in this area is moving towards the development of inexpensive sensors, and also wireless sensors [135] that are integrated with processing units and are called smart sensors [136]. These smart sensors allow one to measure a number of parameters. Such sensors should make it possible to implementation into machines, mechanisms, and tools as part of embedded solutions [137, 138].

A very important direction is the development and application of MEMS technology, which will allow for miniaturisation and cost reduction [139, 140]. Microsensors based on MEMS can be equipped with autonomous power, memory cells, analogue amplification, converter, etc., and can be easily adapted for various applications [141] (Fig. 6).

\subsubsection{CNC control}

During the last several years, a significant stress has been put into research on the development of intelligent, flexible, and easy-to-configure open CNC control systems. In such systems, implementation of monitoring functions has to be easier than in standard CNC control systems. A stress is put on integration of control, monitoring, and CAD systems to obtain possible offline or even online optimisation of a process [142]. However, in most developed approaches, solutions and standards still have to be implemented in practise.

At the same time, an integration of monitoring applications with commercially offered $\mathrm{CNC}$ control has been developed and implemented in industry. Special dedicated monitoring interfaces have been developed by $\mathrm{CNC}$ producers allowing for the integration of some monitoring functions via the human machine interface of CNC control [143]. The development of an open $\mathrm{CNC}$ control makes integration of monitoring with control systems easier than in the past [144, 145]. It is possible to now add customised monitoring functions, connecting it with signals measurement and implementation
Fig. 6 Reconfigurable multisensor monitoring system [19]

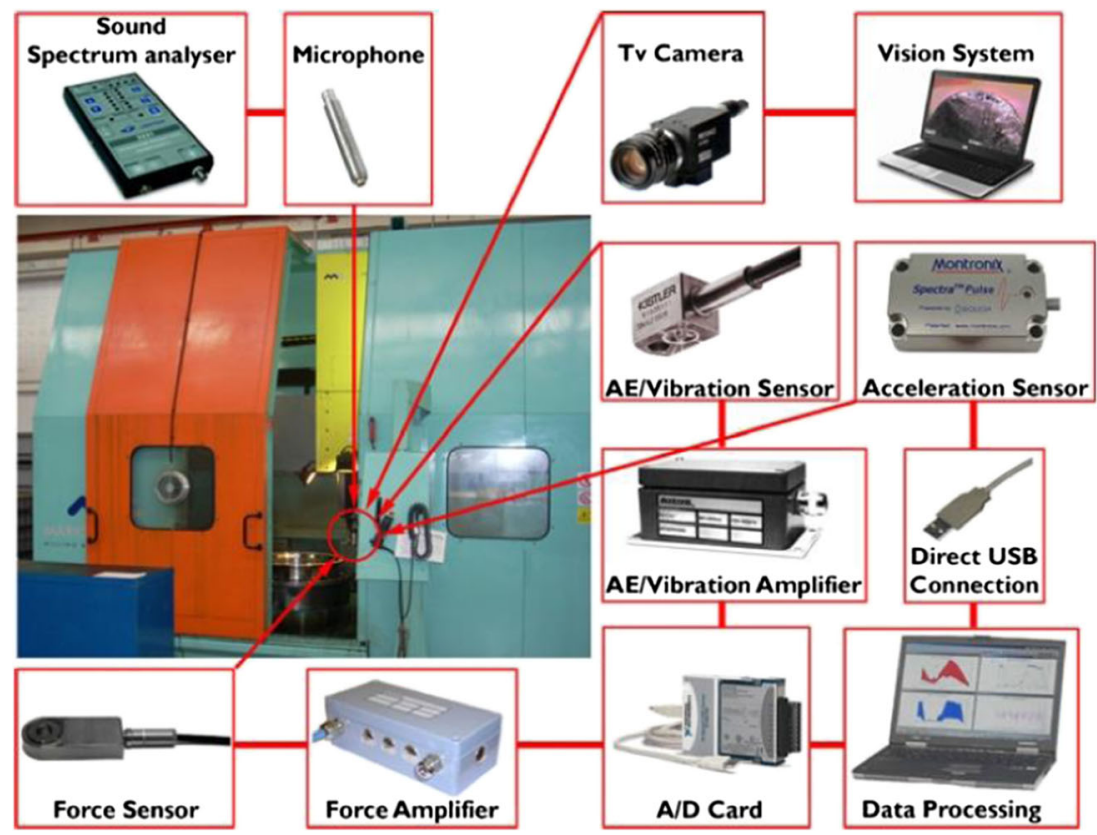


of control functions allowing for optimisation of machine operation or processes [25, 142, 146].

A very interesting direction in CNC development is research on applying a multi-agent philosophy that allows the implementation of intelligence at various levels of the control system [147]. An example is the MADCON system that was developed to simplify the interaction between hardware and software functions, simplifying system customization and allowing for simple integration of control and monitoring functions [148]. However, in spite of a large number of studies, an open CNC control systems, these systems are generally only used in special or retrofitted machines. They are still not used in the mass production of machine tools. Therefore, integration of monitoring and shop floor control systems still have to be based on standard $\mathrm{CNC}$ control systems and function offered by their producers.

\subsubsection{Real-time}

Real-time systems (RTS) have to be applied in all process and devices when system operation depends not only on the logical results, but also on the time at which these results are achieved. Real-time technology can be divided into soft- and hard-real-time. In soft-real-time systems, delays are acceptable, but they increase the cost of system operation. In hard-real-time systems, delays or errors are not acceptable, because such delays can destroy a machine, system, or be dangerous to peoples [149]. In manufacturing, machine control and monitoring usually has to work under hard-real-time constraints. Usually, monitoring systems are built in a hierarchical way. Lower layers are responsible for signal acquisition, and analysis is done by software and hardware working as a hard-real-time system. This is implemented on specialised computer cards based on dedicated DSP processors, dedicated real-time operating systems, and special software [150]. To connect monitoring with a control function, for example to optimise or for process control, most systems have to be built as a realtime system. Apart from acquisition devices that consist of sensors and measurement cards, special controllers, like an advanced PLC or industrial PC have to be used. Controllers operating in real-time operating systems are connected with each other through real-time industrial networks. Software for data analysis, decision support, and control tasks have to work under real-time conditions. Implementation of real time into monitoring systems requires the use of special dedicated devices, like measurement cards operating in real-time conditions. In most cases, solutions connecting sensors, data acquisition, and controllers for rough analysis can be built as an embedded systems [151]. This allows for miniaturisation and radical cost reduction.

\subsubsection{Embedded systems}

Embedded systems are computer systems with dedicated functions within a larger mechanical or mechatronic system. Very often, they work under real-time computing constraints. Such systems are embedded as a part of a complete device. They consist of hardware such as processors, memory, control software, and often mechanical parts, like sensors or actuators [152]. Nowadays, most products, such as telephones, cameras, cars, washing machines, etc., are based on such systems. In the past, embedded systems were built on a small scale and with limited functionality. Current advances in microelectronics and software allow embedded systems to be composed of a large set of processing elements [153].

Development trends are moving towards significant enhanced functionality, complexity, and scalability [154]. Based on wired and wireless networks, connections are being built for large-scale distributed real-time embedded systems (DRES) [155]. Such embedded computing and information technologies have become an enabler for further development of monitoring and control systems. Basing on large-scale distributed real-time embedded systems, it will be possible to build complex integrated monitoring systems to monitor the complete production process. This includes being able to integrate with the control systems of machines and the shop floor.

At a lower level, monitoring systems in real-time embedded solutions will allow for development that includes intelligent sensors combined with data analysis applications. An important research area is in miniaturisation and embedding mechanical systems based on MEMS. Such micro systems could be easily applied to machines, handles, tools, or even manufactured parts.

\subsection{New approaches in systems areas of monitoring} integration

\subsubsection{MTConnect}

A project called MTConnet was started in 2009 by the American Association for Manufacturing Technology being a result of activity focused on integration of monitoring systems [156]. Its goal was to develop an open communication standard between different types of equipment and systems used in manufacturing systems. The aim of the standard is to allow data to be exchanged between different applications and have these applications run over the Internet. The MTConnect standard defines communication between monitoring and control devices and information systems. It is based on the XML standard. Currently, the development of an overall standard is being established especially for this purpose by the MTConnect Institute (http://mtconnect.org/; Fig. 7). 
Fig. 7 An example of

MTConnect object model [157]

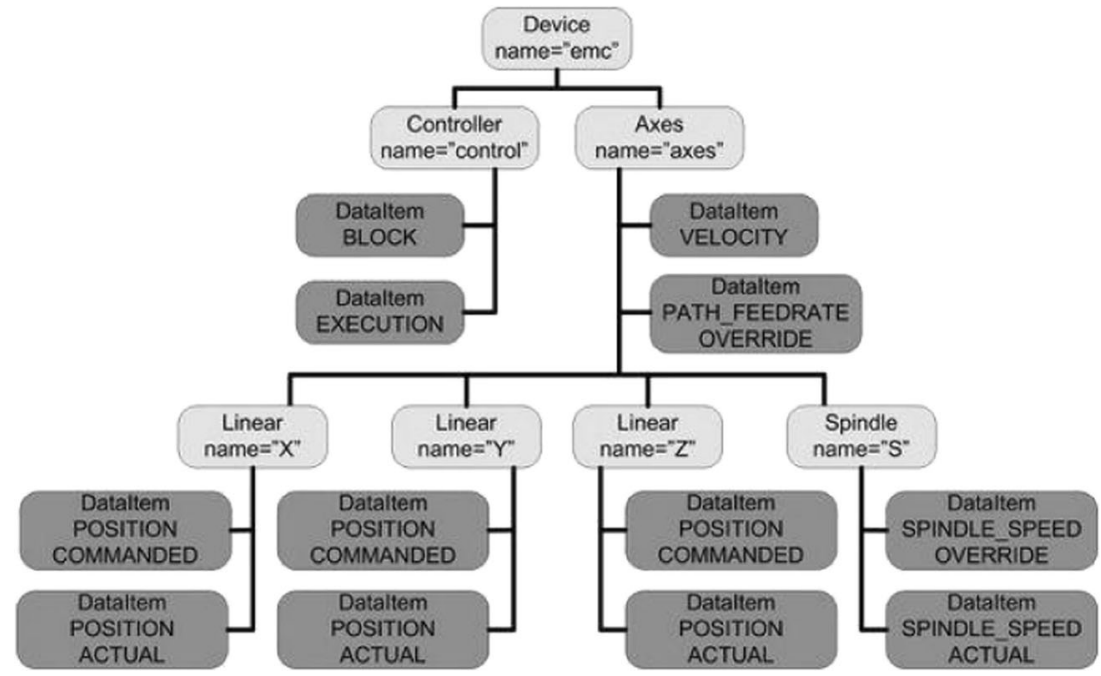

The possibility of easier and cheaper integration of solutions offered by different producers into one system is an advantage of the MTConnect standard. It allows for easy data exchange independently of hardware platform and operating system. A disadvantage of the standard is that it is based on the ICP/IP protocol. This results in a limited data transfer rate and makes it almost impossible to build systems operating under real-time constrains.

There is much research being done based on the MTConnect standard. The aim is to develop integrated monitoring and control systems for manufacturing processes and machine tools. An example is the application of the MTConnect standard to exchange of data between CNC control, a shop floor control system, a companywide IT system, and a special optimisation application. Optimisation of the manufacturing process through comparison of real machining parameters with a CAD/CAM model and according to this, modifying machine parameters is the aim of the system [157].

Another similar system, also based on the MTConnect standard, was developed by Ridwan [158]. It allows for the integration of information from different monitoring systems, analysis and visualisation. Data from the monitoring system is submitted using a standard STEP-NC to the driver, which conducts an optimisation process (Fig. 8).

The project is currently in the research phase, but demonstrates the trend towards monitoring and control integration based on recently developed standards. An interesting example of integration based on MTConnect is a monitoring system for of machine tool energy consumption [111].

\subsubsection{Cloud manufacturing}

Data processing via so-called cloud computing is one of the fastest growing areas of IT systems [159]. According to the definition by National Institute of Standards and Technology (NIST) in the USA), cloud computing is: "a model that allows for ambitious, tailored to needs, attach to the common area network computing resources, that can be shared instantly and released with minimal effort and minimum interaction with the entity offering services" [160] (Fig. 9).

A number of research projects are aim at application of the cloud philosophy to manufacturing systems. The most advanced project is funded under the FP7 EU-project ManuCloud [21]. The aim of this initiative is to develop a model of service oriented, customer centric, and demanddriven manufacturing systems based on cloud computing.

The ManuCloud project is a new direction in development in the area of high-speed, long-distance industrial control systems, and flexible cloud-computing applications for manufacturing. Based on this philosophy, solutions will be able to integrate monitoring into one system that connects different companies together along the whole supply chain

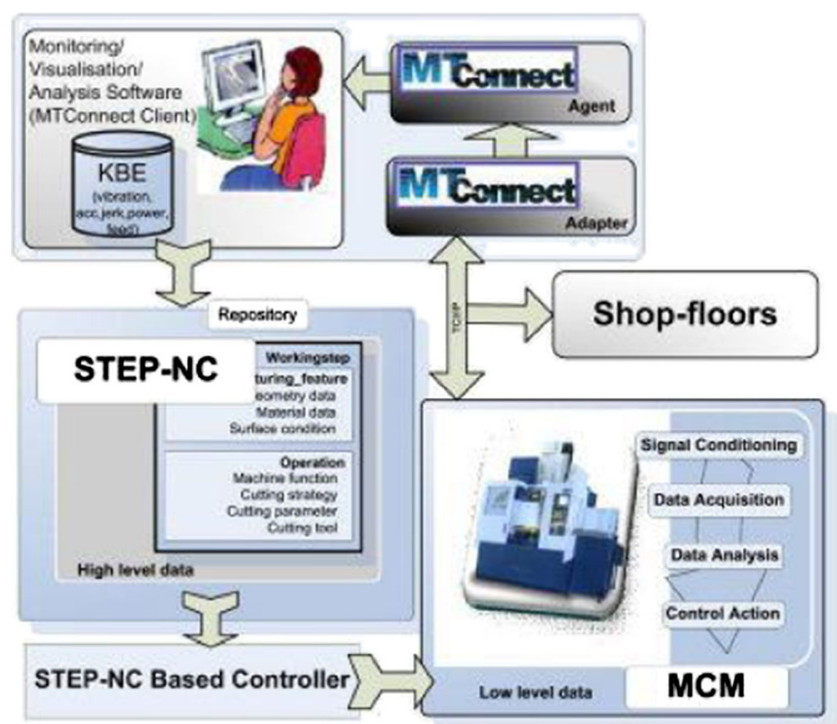

Fig. 8 Structure of integrated monitoring and optimisation system based on MTConnect and STEP-NC standard [157] 


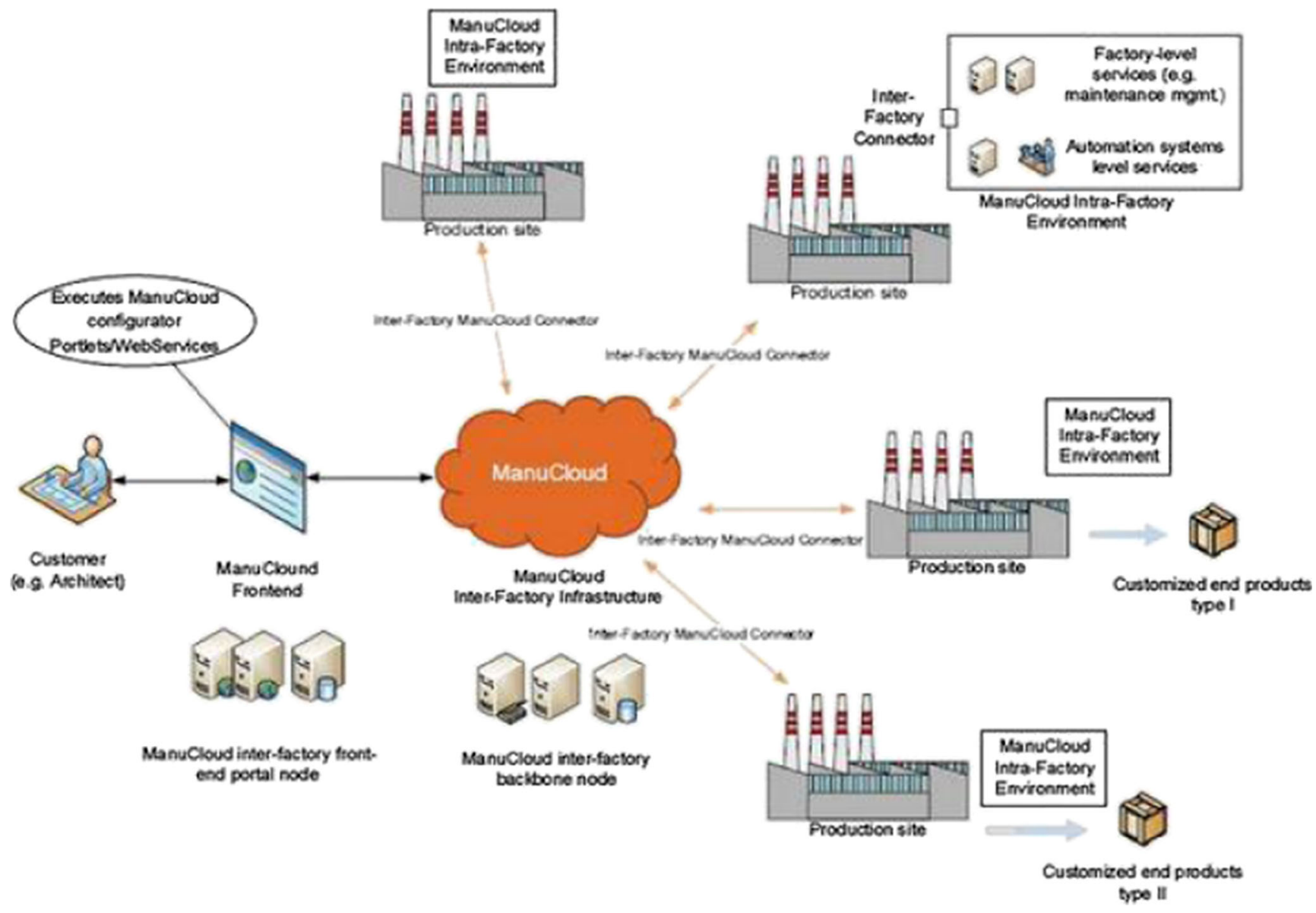

Fig. 9 Cloud manufacturing architecture-ManuCloud project [22]

of a production process. Other examples of research in the area of application of cloud computing to manufacturing include $[161,162]$.

The rapid development of cloud applications in most domains, such as for telecommunication, programming, management, and private life will put increasing pressure on manufacturing to meet similar expectations. Cloud manufacturing will most likely develop in the direction of data processing, orders management, supply chain organisation, and also provide systems management and control by external suppliers. A key aspect is the integration of monitoring and control of machines and production systems. The implementation of remote order management and outsourcing in manufacturing based on cloud manufacturing will require remote access to the results of completed orders, as well as the history of system capabilities and availability. This will be one of the key factors forcing both equipment suppliers and manufacturers to integrate monitoring applications into complex remotely available systems. An example of such a system is machine availability monitoring systems based on a cloud solution [163] or a monitoring system where data presentation is built as a cloud service [164].
5.4 Software solutions for integration of monitoring systems

\subsubsection{Integration based on client-server technology}

The client-server architecture was developed and popularised at the beginning of the 1990s [165] and is still the most popular architecture in IT systems. Company-wide IT systems are often built based on this concept, as well as various kinds of applications supporting manufacturing systems. Such systems are based on a common database or system core working as a server that offers services for other parts of the systems working as a client [166]. The advantages of such systems include well-known technology, a large number of systems, and programming tools supporting application development (Fig. 10).

Client-server technology allows one to build centralised applications where the server is a central part of the system, where most of the data operations are performed. Centralisation brings many advantages, including data integrity, a relatively simple architecture, and easy control of system operations [167]. There are, however, also significant disadvantages of a centralised structure. It has low flexibility, is difficult to reconfiguration, has complicated 
Fig. 10 Centralised and decentralised systems
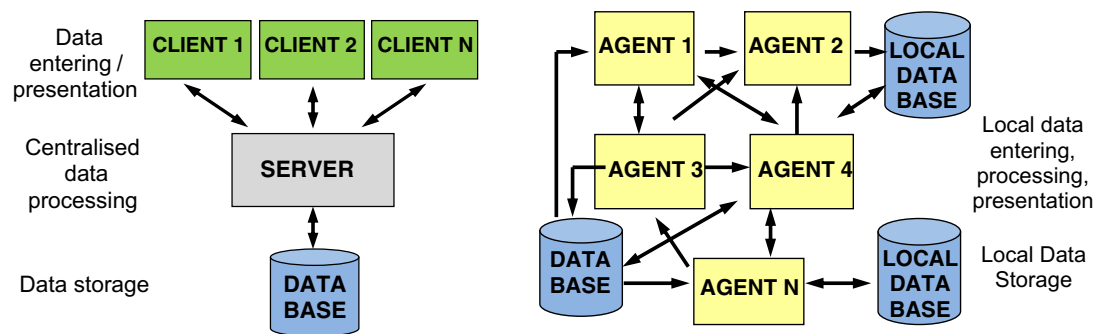

implementation of modular structures or various control algorithms, and high costs when building dedicated systems [168]. For manufacturing applications, an important disadvantage of client-server technology is a problem with implementation of real-time conditions necessary for processing data and control at the machine level. Servers operating on SQL or this kind of technology based on Unix or Windows operating systems are not real-time systems [169]. The need to connect the main system with separate applications makes building of a realtime environment very difficult.

Large integrated IT systems for the shop floor level in manufacturing are difficult to be built in client-server technology. As such, much of the information exchange between operators is currently done through paper reports for both control and monitoring. In practice, client-server technology can be built for dedicated control and monitoring systems that are static and do not often require changes such as adding new machines, adding functions, etc. This approach for large integrated solutions is expensive, inflexible, and is vulnerable to unexpected malfunctions. In modern, agile companies, where flexibility and the ability to make changes and decisions, client-server-based technology is really only suited for localised applications, rather than as a base for a large complex system.

\subsubsection{Integration based on SCADA systems}

SCADA are widely used in process industry monitoring and control [170]. There are large numbers of SCADA development environments offed by PLC producers and specialised software companies. Some open-source systems are also available [171]. A SCADA system has significant potential for integration in the manufacturing process. Such a systems, however, are built and optimised for control of relatively simple decentralised systems, like those in the process industry, pipeline systems, electrical grid, etc. [172, 173] (Fig. 11).

Security plays a crucial role in these systems, but usually the whole system does not need to operate under hard realtime conditions [175]. In these kinds of applications, a realtime system can operate just at the PLC level. Generally, SCADA systems do not meet the requirements of manufacturing systems, like flexibility, ability to implement complex algorithms for data processing and analysis, control for decision taking, and operation under hard-real-time constraints.
SCADA systems are based on PC operating systems, usually Windows or Unix. This makes implementation easy in an office environment were monitored data area are presented and control decisions are taken, by connecting it to the PLC. The main problem with these systems lies in integration and implementation into advanced monitoring systems, because of the difficulty in meeting real-time system requirements. As such, components need to be built separately based on PLC, industrial PC, etc., and then connected to SCADA components [172].

As a result, there are no advanced monitoring systems connected with control functions based only on SCADA in manufacturing. However, it is possible to build dedicated monitoring systems where some SCADA functions are used, especially for acquisition of simple monitoring signals, communication with a PLC, system interface (HMI), databases, alarm management, etc. These systems have to be supported by dedicated applications that allow for signal conditioning, processing and further evaluation by cognitive decisionmaking support systems for a final diagnosis that can be presented, archived, and managed by SCADA [176].

\subsubsection{Multi-agent systems}

Multi-agent technology is the name of a distributed artificial intelligence technique based on autonomous entities called agents. An agent is a logical object that can independently

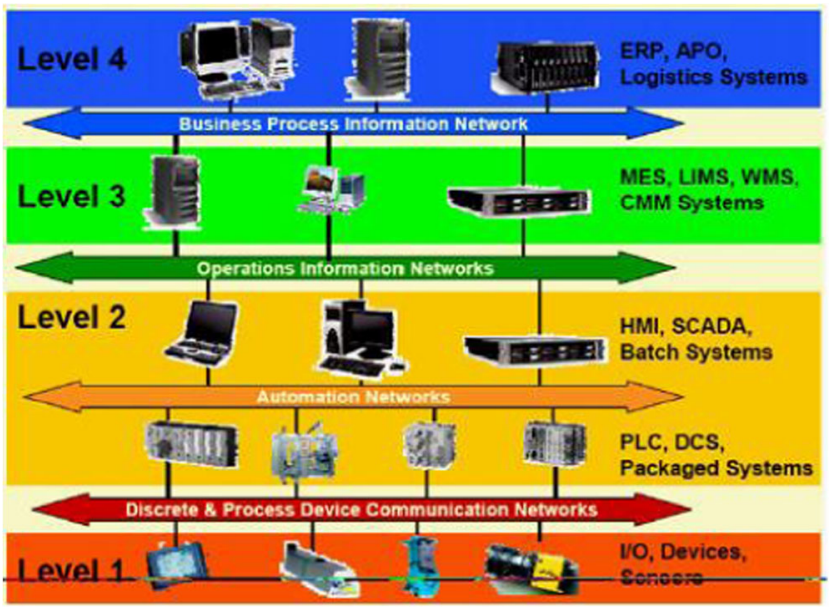

Fig. 11 SCADA systems in the industrial control hierarchy according to ISA ' 95 model [174] 
perform its own job and cooperate with other agents to perform larger tasks [177]. An agent that is coded as a piece of software can have its own "intelligent" algorithm to solve local problems and perform local optimisation [178]. Multiagent applications are very well suited to complex systems with a high ratio of disturbances. Problems can be solved locally with minimum influence on the whole system [179].

The important advantage of multi-agent systems when seen from the point of view of building integrated monitoring is the possibility of dynamic management of the system [180]. Agents can be added and removed from the system without switching its operation. This allows for easy reconfiguration of the system by adding new modules, functions, or tasks, and allows for the building of flexible, intelligent distributed systems [181]. The multi-agent philosophy is very well suited for building shop floor control systems for manufacturing [182]. There is considerable research in this area [27, 182-187]. Usually, these systems have a relatively simple monitoring module to control the status of the machine and process. An interesting research area is application of agent technology for optimization, mostly into system description and simulation [188]. Most multi-agent systems are based on special multiagent platforms that allow for easy creation of agents, their management, and standardised communication. An example of this is the Java Development Framework (JADE) [189]. This follows standards developed and recommended by The Foundation of Intelligent Physical Agents (FIPA), which is a Standards Committee of the IEEE Computer Society [190] (Fig. 12).

The main advantage of multi-agent systems from the perspective of building complex integrated monitoring and supervision systems includes easy implementation of various intelligent algorithms, easy reconfiguration of the system by adding or removing agents or algorithms, and easy implementation of robust distributed solutions [178]. The simple modularisation of systems based on multi-agent philosophy is also key. This allows for the building of systems based on

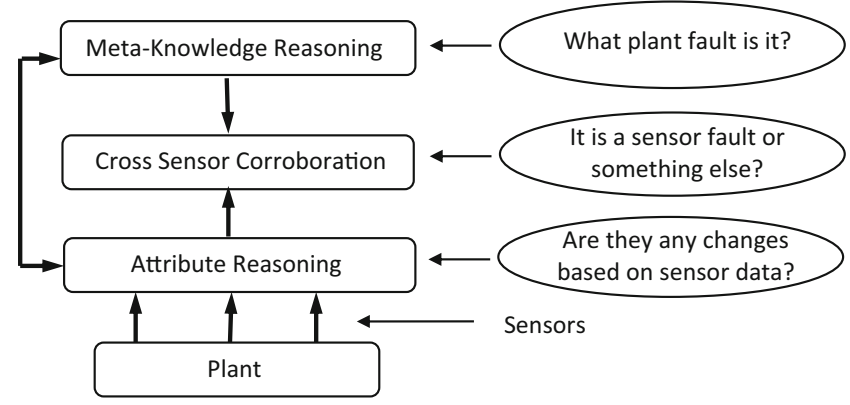

Fig. 13 Logical structure of COndition Monitoring Multi Agent System (COMMAS) [193]

standardised modules that will allow for significant reduction of development and implementation cost [192].

\subsubsection{Application of multi-agent systems in monitoring}

Multi-agent technology is especially interesting for building integrated advanced monitoring systems. The implementation of a multi-agent philosophy would allow for development of complex, intelligent, distributed applications connecting various monitoring devices to one system [23]. Multi-agent applications for manufacturing systems usually focus on shop floor control with limited monitoring functions. An example is "Operator 2.0 " system that is based on multi-agent philosophy and IEC 62264 specifying control systems architecture [164] (Fig. 13).

Quite a bit of research has focused on the development of multi-agent based systems for maintenance in the process and power industry. In this sector, data acquisition is relatively simple, but the problem is geographical dispersion. The COndition Monitoring Multi Agent System (COMMAS) is one of the most developed multi-agent systems in this area and, importantly, has been implemented in practise [46].

This system is based on a three-layer architecture divided into an attribute reasoning agent (ARA), cross-sensor corroboration agents (CSCA), and metaknowledge reasoning agents
Fig. 12 Example of intelligent agent-based monitoring and maintenance system [191]

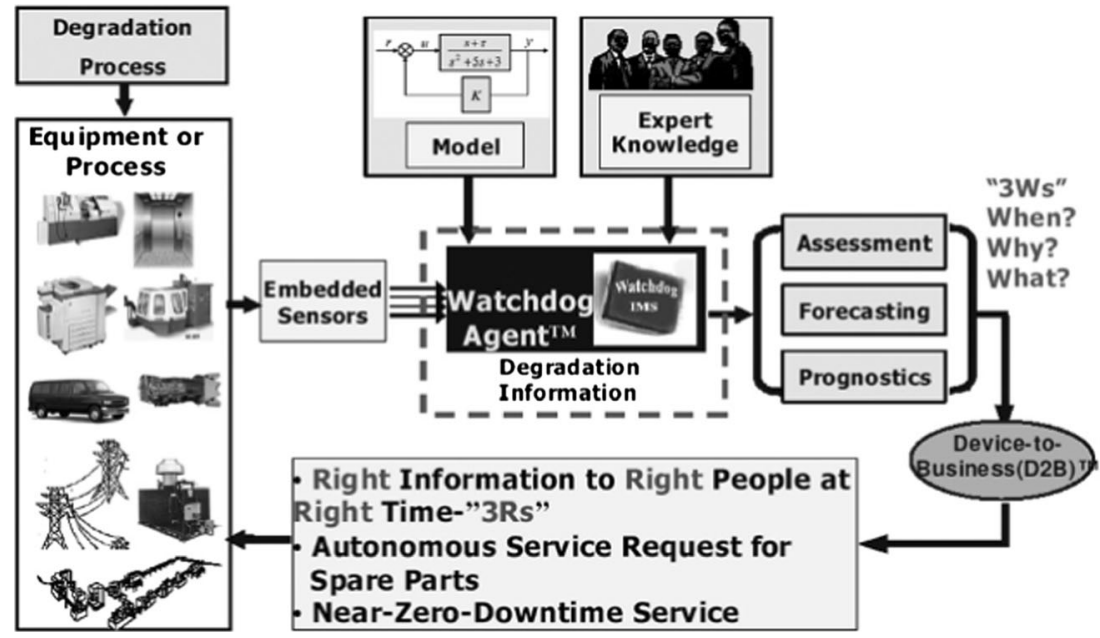


(MKRA) [193]. The ARA layer agents are connected directly to sensors and notice deviations in signals. The CSCA layer analyses information from the ARA, verifies that sensors are working correctly, check for possible failure, and tries to find reasons for abnormal signal levels. The MKRA layer is an inference engine that has an overall view of the whole system and evaluates the state of the plant base on information from the ARA and CSCA layers. The COMMAS system was developed over several years, and was finally implemented in the ZEUS Agent Building Toolkit [194]. COMMAS was implemented to monitor a gas turbine start-up sequence and to identify partial discharge signals emanating from defects in extra high-voltage gas insulated switchgear (GIS) at power substations [195].

The system was further implemented to monitor high power transformers. It was developed to monitor equipment at
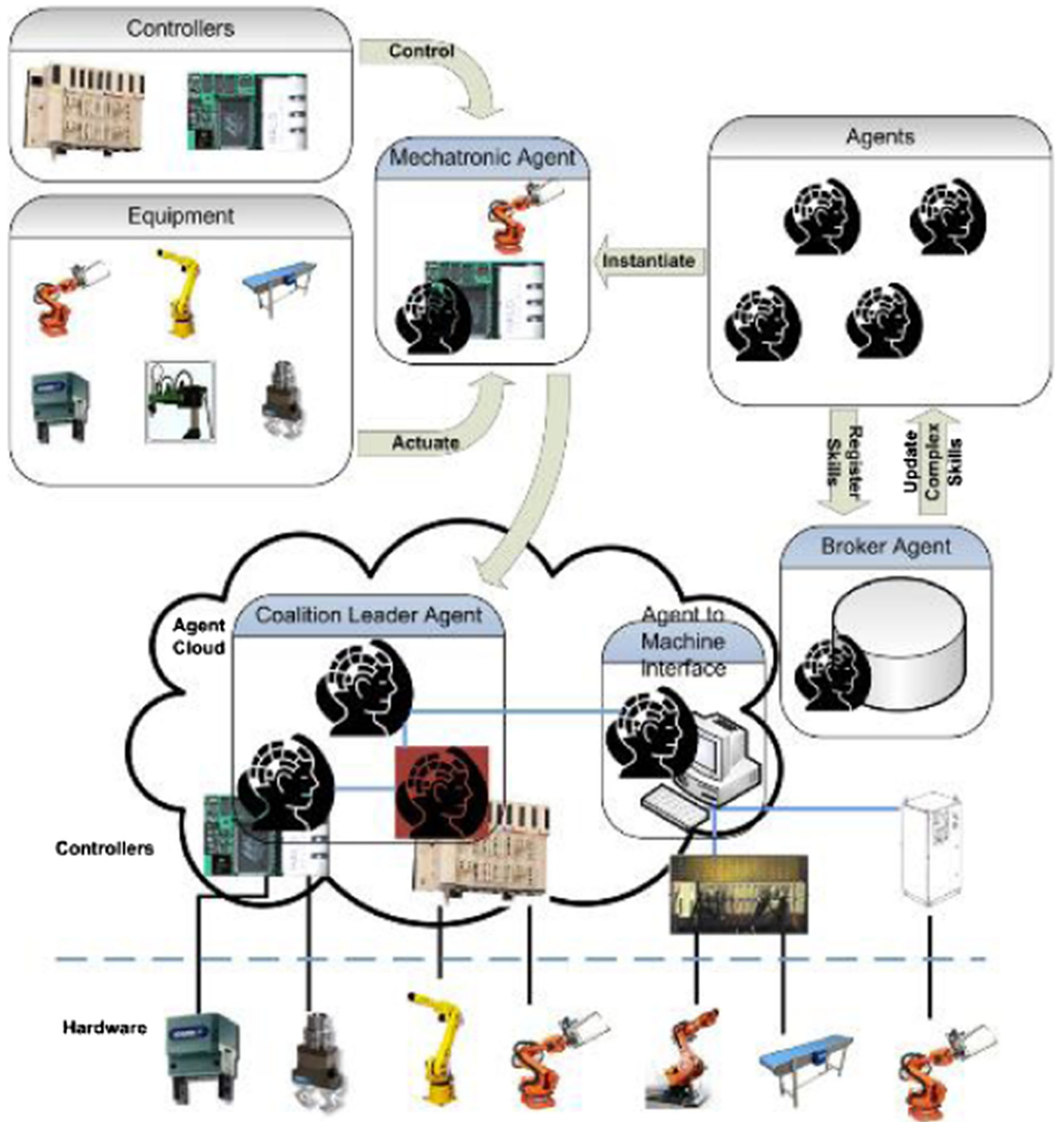

Fig. 14 Model of agent-based model manufacturing control system - a vision of a new distributed, intelligent production paradigm [32] 
different locations and to use a number of conditionmonitoring techniques [196]. Described systems were developed for the process industry where monitoring is relatively simple in comparison to machining processes, like cutting or milling. However, it shows the potential of multi-agent technology for building integrated monitoring systems dedicated to a machining process (Fig. 14).

\subsubsection{Integration based on multi-agent systems-research direction}

Applying multi-agent technology to integration of monitoring in machining systems is a major challenge that has not yet been well addressed. There are only a few publications in this area. Most are focused on solving particular problems important for building complex systems. An example is a multiagent framework based on smart sensors and actuators developed for machine tool control and monitoring [147]. Another paper addresses the need for modular component-based diagnosis frameworks for modular manufacturing systems. A multi-agent distributed diagnostic framework operating based on a Bayesian algorithm was also proposed [197]. An attempt to build agent-based interaction-oriented shop floor systems to support emergent diagnosis is another example [198].

Multi-agent systems have a significant number of advantages important for IT systems used for manufacturing. Systems based on a multi-agent philosophy have been researched for almost two decades. During that time, many special toolkits have been developed to support application development. A number of systems have been implemented in various production companies, and also in the area of maintenance and monitoring in the process industry. As such, the time is ripe for the development of integrated advanced multi-agent monitoring systems for manufacturing systems, and for the machining industry as well.

\section{Conclusions}

Advanced monitoring systems developed for the monitoring of the manufacturing process should allow for efficient support of complex-product machining. Machine and tool condition monitoring enables the detection of most problems and allows for high accuracy in machining and high availability for machines. However, as shown in the latest literature reviews, there is shortfall in IT solutions that can effectively handle complex and advanced monitoring systems that would integrate various monitoring and supervision applications into one system. Integration of information flows about a company and production at the management level is a standard for almost all contemporary companies. New IT solutions based on Internet and cloud computing allow for easier integration of various IT systems. Integrated systems can now be configured according to current needs, for example in the frame of a supply chain or a product development network. At the same time, however, currently there is no possibility to exchange information between various advanced monitoring systems. Moreover, the building of a companywide monitoring system that facilitates a synergy effect to support production and to collect a history of parts production is very difficult.

This research review shows the potential areas for advanced integrated monitoring systems development. The analysis indicates several development directions that include sensors, CNC systems, new approaches in communication standards, and software solutions. The new direction based on multi-agent systems is very promising. There has been significant research and industrial implementation of monitoring and maintenance in process industry, the chemical industry, and power energy systems. The experience in developing these systems forms a base for the integration of advanced monitoring of the machining process. The direction forward will have to combine advanced tools, machine, and workpiece condition monitoring, maintenance functions, processes, and product history archiving. Systems will have to be integrated with advanced IT systems operating at both the management and supply chain level, and will thus likely be based on cloud computing.

Acknowledgments Support of Structural Funds in the Operational Programme - Innovative Economy (IE OP) financed from the European Regional Development Fund Project "Modern material technologies in aerospace industry", Nr POIG.01.01.02-00-015/08-00 is gratefully acknowledged.

Open Access This article is distributed under the terms of the Creative Commons Attribution License which permits any use, distribution, and reproduction in any medium, provided the original author(s) and the source are credited.

\section{References}

1. Coe N, Hess M (2013) Global production networks, labour and development. Geoforum 44:4-9

2. Teller J, Kock A (2013) An empirical investigation on how portfolio risk management influences project portfolio success. Int J Proj Manag 31:817-829

3. Mason R, Lalwani C (2008) Mass customised distribution. Int J Prod Econ 114:71-83

4. Yang LR (2013) Key practices, manufacturing capability and attainment of manufacturing goals: the perspective of project/ engineer-to-order manufacturing. Int J Proj Manag 31(1):109-125

5. Herron C, Hicks C (2008) The transfer of selected lean manufacturing techniques from Japanese automotive manufacturing into general manufacturing (UK) through change agents. Robot Comput Integr Manuf 24:524-531

6. Van Veen-Dirks P (2005) Management control and the production environment: a review. Int J Prod Econ 93-94:263-272 
7. Camarinha-Matos LM, Afsarmanesh H et al (2009) Collaborative networked organizations - concepts and practice in manufacturing enterprises. Comput Ind Eng 57:46-60

8. The Relocation of Production Activities (2005): Trends and drivers, The EU Economy, Review

9. Oborski P (2012) Transformations taking place in manufacturing companies. Inzynieria Maszyn R. 17(z. 1):7-16

10. Nagalingam S, Lin G (2008) CIM-still the solution for manufacturing industry. Robot Comput Integr Manuf 24:332344

11. Wang L (2008) Wise-shop floor: an integrated approach for webbased collaborative manufacturing. IEEE Trans Syst Man CybernetPart C: Appl Rev 38(4):562-573

12. Gunasekaran H (1999) Agile manufacturing: a framework for research and development. Int J Prod Econ 62(8):7-105

13. Brussel HV, Wyns J, Valckenaers P, Bongaerts L (1998) Reference architecture for holonic manufacturing systems: PROSA. Comput Ind 37(3):255-274

14. Warnecke HJ (1993) The fractal company: a revolution in corporate culture. Springer, Berlin

15. Mun J, Ryu K, Jung M (2006) Self-reconfigurable software architecture: design and implementation. Comput Ind Eng 51:163-173

16. Dornfeld D (2012) Green manufacturing: fundamentals and applications. Springer, New York

17. Ahn SH, Chun DM, Chu WS (2013) Perspective to green manufacturing and applications. Int J Precis Eng Manuf 14(6): 873-874

18. Byrne G, Dornfeld D, Inasaki I, Konig W, Teti R (1995) Tool condition monitoring - the status of research and industrial application. CIRP Ann 44(2):541-567

19. Teti R, Jemielniak K, O’Donnell G, Dornfeld D (2010) Advanced monitoring of machining operations. CIRP Ann Manuf Technol 59: 717-739

20. Cheng K, Bateman RJ (2008) e-Manufacturing: characteristics, applications and potentials - review. Prog Nat Sci 18:1323-1328

21. Wu D, Greer MJ, Rosen D, Schaefer D (2013) Cloud manufacturing: strategic vision and state-of-the-art, J Manuf Syst, ISSN 0278-6125

22. Meier M, Seidelmann J, Mezgár I (2010) ManuCloud: the nextgeneration manufacturing as a service environment. Eur Res Cons Inform Math News 83:33-34

23. Metzger M, Polakow G (2011) A survey on applications of agent technology in industrial process control. IEEE Trans Ind Info 7:4

24. Campos J (2009) Development in the application of ICT in condition monitoring and maintenance. Comput Ind 60:1-20

25. Oliveira JF, Ferraz F, Coelho RT, Silva EJ (2008) Architecture for machining process and production based in open CNC. Proc IMechE J Eng Manuf 222(12):1605-1612

26. Jemielniak K (2012) Automatic tool condition monitoring. Inzynieria Maszyn R.17(z.1):17-29

27. Morel G, Valckenaers $P$ et al (2007) Manufacturing plant control challenges and issues. Control Eng Pract 15:1321-1331

28. Park S (2004) High frequency bandwidth cutting force measurements in milling using the spindle force sensor system. $\mathrm{PhD}$ thesis, University of British Columbia, Vancouver, Canada

29. Hauser DP, de Weck OL (2007) Flexibility in component manufacturing systems: evaluation framework and case study. J Intell Manuf 18:421-432

30. Milberg J, Koch M (1994) Autonomous manufacturing systemspast, present and future of FMS. Manuf Syst 23(4):279-289

31. John M, Gross JM (2002) Fundamentals of preventive maintenance, AMACOM Div Am Mgmt Assn

32. Ribeiro L, Barata J (2011) Re-thinking diagnosis for future automation systems: an analysis of current diagnostic practices and their applicability in emerging IT based production paradigms. Comput Ind 62:639-659
33. Mishra RC (2006) Reliability and maintenance engineering, New Age Int

34. Muller A, Marquez AC, Iung B (2008) On the concept of emaintenance: review and current research. Reliab Eng Syst Saf 93:1165-1187

35. Iung B, Levrat E, Marquez AC, Erbe H (2009) Conceptual framework for e-maintenance: illustration by e-maintenance technologies and platforms. Annu Rev Control 33:220-229

36. Persona A, Regattieri A, Pham H, Battini D (2007) Remote control and maintenance outsourcing networks and its applications in supply chain management. J Oper Manag 25:1275-1291

37. Jantunen E, Emmanouilidis C, Arnaiz A, Gilabert E (2010) Economical and technological prospects for e-maintenance. Int $\mathrm{J}$ Syst Assur Eng Manag 1(3):201-209

38. Lee J (1997) Strategy and challenges on remote diagnostics and maintenance for manufacturing equipment, Proc Ann Reliab Maintainability Symp, 368-370

39. Lee J (2001) A framework for web-enabled e-maintenance systems, Proc Second Int Symp Environ Conscious Des Inverse Manuf, 450-459

40. Sun JG, Yang XB, Huang D (2002) Multi-agent based distributed chemical process monitoring and diagnosis. Proc 2002 Int Conf Mach Learn Cybern 2:851-856

41. Kunze U (2003) Condition tele monitoring and diagnosis of power plants using web technology. Prog Nucl Energy 43:129-136

42. Wiliem L et al. (2006) Development of Internet based real-time water condition monitoring system. Proc 19th Intern Cong Exhibition Con Mon Diag Eng Man (COMADEM 2006), 119-129

43. Campos J, Jantunen E, Prakash O (2007) Development of a maintenance system based on web and mobile technologies. J Int Technol Info Manag 16(4):1-8

44. Wang W, Tse PW, Lee J (2007) Remote machine maintenance system through Internet and mobile communication. Int $\mathrm{J} \mathrm{Adv}$ Manuf Technol 31(7-8):783-789

45. Fu C et al (2002) MAS-based model of intelligent controlmaintenance-management system (ICMMS) and its application. Proc 2002 Intern Conf Mach Learn Cybern 1:376-380

46. Mangina E, McArthur S, McDonald J, Moyes A (2001) COMMAS (COndition-Monitoring Multi-Agent System). J Auton Agents Multi-Agent Syst 4:279-281

47. Byrne G, Dornfeld D, Denkena B (2004) Advancing cutting technology. CIRP Ann 52(2):483-507

48. Jun M, Ozdoganlar B, DeVor R, Kapoor S, Kirchheim K, Schaffner G (2002) Evaluation of a spindle-based force sensor for monitoring and fault diagnosis of machining operations. Int $\mathrm{J}$ Mach Tools Manuf 42:741-751

49. Klocke F, Kratz S, Veselovac D, Arrazola P (2008) Investigation on force sensor dynamics \& their measurement characteristics. International Mechanical Engineering Congress \& Exp, Boston, pp 2-6

50. Klocke F, Wirtz G, Veselovac D (2008) Design approach for adaptive axial force control in gun drilling. ASME International Mechanical Eng. Congress and Expos, Boston

51. Salgado DR, Alonso FJ (2007) An approach based on current and sound signals for in-process tool wear monitoring. Int J Mach Tools Manuf 47:2140-2152

52. Korkut I (2003) A dynamometer design and its construction for milling operation. Mater Des 24:631-637

53. Smith DA, Smith S, Tlusty J (1998) High performance milling torque sensor. J Manuf Sci Eng 120:504-514

54. Davies M, Ueda T, M’Saoubi R, Mullany B, Cooke A (2007) On the measurement of temperature in material removal processes. CIRP Ann 56(02):581-604

55. Mannan M, Broms S (1992) Investigating the temperature dependence of motor current measurements applied to monitoring and adaptive control. CIRP Ann 41(1):451-454 
56. Arrazola PJ, Arriola I, Davies MA, Cooke AL, Dutterer BS (2008) The effect of machinability on thermal fields in orthogonal cutting of AISI 4140 steel. CIRP Ann 57(1):65-68

57. Jemielniak K (2001) Some aspects of acoustic emission signal preprocessing. J Mater Process Technol 109:242-247

58. Donohue B, McCormac B, Geraghty D, O'Donnell GE (2008) An investigation into the development of surface acoustic wave (SAW) devices as strain sensors. 25th International Manufacturing Conference, Dublin, pp 575-582

59. Rogers L (1979) The application of vibration analysis and acoustic emission source location to on-line condition monitoring of antifriction bearings. Tribol Int, 51-59

60. Alonso F, Salgado D (2008) Analysis of the structure of vibration signals for tool wear detection. Mech Syst Signal Process 22: 735-748

61. Mannan M, Kassim A, Jing M (2000) Application of image and sound analysis techniques to monitor the condition of cutting tools. Pattern Recogn Lett 21:969-979

62. Lee DJ, Kim SH, Ahn JH (2004) Breakage detection of smalldiameter tap using vision system in high-speed tapping machine with open architecture controller. KSME Int J 18(7):1055-1061

63. Dimla DE (2000) Sensor signals for tool-wear monitoring in metal cutting: a review of methods. Int $\mathrm{J}$ Mach Tools Manuf 40: 1073-1098

64. Kuljanic E, Sortino M, Totis G (2009) Development of an intelligent multisensor chatter detection in milling. Mech Syst Signal Process 23(5):1704-1718

65. Klocke F, Kuljanic E, Wirtz G, Totis G, Veselovac D, Sortino M (2008) Development of an intelligent cutter for face milling. International Conference AMST '08, Udine

66. Auchet S, Chevrier P, Lacour M, Lipinski P (2004) A new method of cutting force measurement based on command voltages of active electro-magnetic bearings. Int J Mach Tools Manuf 44:1441-1449

67. Shinno H, Hashizume H (2003) Sensor-less monitoring of cutting force ultraprecision machining. CIRP Ann 52(1):303-305

68. Verl A, Heisel U, Walther M, Maier D (2009) Sensorless automated condition monitoring for the control of the predictive maintenance of machine tools. CIRP Ann 58:375-378

69. Franco-Gasca LA (2006) Sensorless tool failure monitoring system for drilling machines. Int J Mach Tools Manuf 46:381-386

70. Jemielniak K, Bombiński S (2006) Hierarchical strategies in tool wear monitoring. Proc IMechE 220/B:375-381

71. Jemielniak K, Teti R, Kossakowska J, Segreto T (2006) Innovative signal processing for cutting force based chip form prediction, 2nd Virtual Int Conf. IPROMS, 7-12

72. Abu-Zahra N, Yu G (2000) Analytical model for tool wear monitoring in turning operations using ultrasound waves. Int J Mach Tool Manuf 40:1619-1635

73. Abellan-Nebot J, Subirón R (2010) A review of machining monitoring systems based on artificial intelligence process models. Int $\mathrm{J}$ Adv Manuf Technol 47:237-257

74. Caralon T, Kidd S, Hand D, Wilcox S, Wilkinson P, Barton J, Jones J, Reuben R (1997) AE monitoring of tool wear during the face milling of steels and aluminium alloys using a fibre optic sensor, part 1: energy analysis. IMechE 211:299-309

75. Jeong Y-H, Cho D-W (2002) Estimating cutting force from rotating and stationary feed motor currents on a milling machine. Int J Mach Tools Manuf 42:1559-1566

76. Scheffer C, Heyns P (2004) An industrial tool wear monitoring system for interrupted turning. Mech Syst Signal Process 18: 1219-1242

77. Li X, Ouyang G, Liang Z (2008) Complexity measure of motor current signals for tool flute breakage detection in end milling. Int $\mathrm{J}$ Mach Tools Man 48:371-379

78. Chen X, Li B (2007) AE method for tool condition monitoring based on wavelet analysis. Int J Adv Manuf Technol 33:968-976
79. Kunpeng Z, Wong YS, Hong GS (2009) Wavelet analysis of sensor signals for tool condition monitoring - a review and some new results. Int J Mach Tools Manuf 49:537-553

80. Jemielniak K, Bombinski S, Aristimuno P (2008) Tool condition monitoring in micromilling based on hierarchical integration of signal measures. CIRP Ann 57(1):121-124

81. Zhu K, Wong YS, Hong GS (2009) Multi-category micro-milling tool wear monitoring with continuous hidden Markov models. Mech Syst Signal Proc 23:547-560

82. Gandarias E, Dimov S, Pham DT, Ivanov A, Popov K, Lizarralde R, Arrazola PJ (2006) New methods for tool failure detection in micromilling. Proc IMechE 220(2):137-144

83. Venuvinod PK, Djordjevich A (1996) Towards active chip control. CIRP Ann 45(1):83-86

84. Grzesik W, Bernat P (1998) An investigation of the cutting process for chip breaking monitoring in turning of steels. J Manuf Sci Eng 120(3):555-562

85. Tangjitsitcharoen S (2009) In-process monitoring and detection of chip formation and chatter for CNC turning. J Mater Process Technol 209(10):4682-4688

86. Teti R, Jawahir I, Jemielniak K, Segreto T, Chen S, Kossakowska J (2006) Chip form monitoring through advanced processing of cutting force sensor signals. CIRP Ann 55(1):75-80

87. D'Addona D, Keshari A, Teti R (2008) Spectrum estimation and processing of cutting force sensor signals for chip form monitoring and classification, 4th Virtual International Conference on IPROMS, 555-560

88. Byrne G, O'Donnell G (2007) An integrated force sensor solution for process monitoring of drilling operations. CIRP Ann 56(01):8992

89. Karpuschewski B, Wehmeier M, Inasaki I (2000) Grinding monitoring system based on power and AE sensing. CIRP Ann 49(1):235-240

90. Song DY, Otani N, Aoki T, Kamakoshi Y, Ohara Y, Tamaki H (2005) A new approach to cutting state monitoring in end-mill machining. Int J Mach Tools Manuf 45:909-921

91. Yoon M, Chin D (2005) Cutting force monitoring in the endmilling operation for chatter detection. J Eng Manuf 219(B):455-645

92. Shi D, Axinte D, Gindy N (2007) Development of an online machining process monitoring system: a case study of the broaching process. Int J Adv Manuf Technol 34(1-2):34-46

93. Rubio EM, Teti R (2009) Cutting parameters analysis for the development of a milling process monitoring system based on audible energy sound. J Intell Manuf 20(1):43-54

94. Abouelatta O, Madl J (2001) Surface roughness prediction based on cutting parameters and tool vibration in turning. $\mathrm{J}$ Mater Process Technol 118:269-277

95. Axinte D, Gindy N, Fox K, Unanue I (2004) Process monitoring to assist the workpiece surface quality in machining. Int $\mathrm{J}$ Mach Tools Manuf 44:1091-1098

96. Guo Y, Ammula S (2005) Real-time AE monitoring for surface damage in hard machining. Int J Mach Tools Manuf 45:1622-1627

97. Chang HK, Kim JH, Kim H, Jang DY, Han DC (2007) In-process surface roughness prediction using displacement signals from spindle motion. Int J Mach Tools Manuf 47:1021-1026

98. Marinescu I, Axinte D (2008) A critical analysis of effectiveness of acoustic emission signals to detect tool and workpiece malfunctions in milling operations. Int J Mach Tools Manuf 48:1148-1160

99. Salgado DR, Alonso FJ, Cambero I, Marcelo A (2009) In-process surface roughness prediction system using cutting vibrations in turning. Int J Adv Manuf Technol 43:40-51

100. Marinescu I, Axinte D (2009) A time-frequency AE-based monitoring technique to identify workpiece surface malfunctions in milling with multiple teeth cutting simultaneously. Int $\mathrm{J}$ Mach Tools Manuf 49:53-65

101. Tansel I, Yapici A (2013) Part based process performance monitoring (PbPPM). J Manuf Process 15:329-337 
102. Van Houten F, Kimura F (2000) The virtual maintenance system: a computer-based support tool for robust design product monitoring. Fault Diagn Maint Plan CIRP Ann 49(1):91-94

103. Choudhury S (2001) On-line monitoring of tool wear \& control of dimensional inaccuracy in turning. J Manuf Sci Eng 123(1):10-12

104. Axinte D, Gindy N (2004) Assessment of the effectiveness of a spindle power signal for tool condition monitoring in machining processes. Int J Prod Res 42:2679-2691

105. O'Donnell GE, Kelly K, Byrne G (2000) Use of a sensor integrated motor spindle for monitoring of a flexible machining centre, 2nd edn. IRP Int. Sem. On ICME, Capri, pp 383-388

106. Saravanan S, Yadava G, Rao P (2006) Condition monitoring studies on spindle bearing of a lathe. Int J Adv Manuf Technol 28: 993-1005

107. Quintana G, Garcia-Romeu ML, Ciurana J (2011) Surface roughness monitoring application based on artificial neural networks for ball-end milling operations. J Intell Manuf 22: 607-617

108. Marinescu V, Constantin I, Apostu C, Marin FB, Banu M, Epureanu A (2011) Adaptive dimensional control based on in-cycle geometry monitoring and programming for $\mathrm{CNC}$ turning center. Int $\mathrm{J}$ Adv Manuf Technol 55:1079-1097

109. Kruger M, Denkena B (2013) A model-based approach for monitoring of shape deviations in peripheral milling. Int J Adv Manuf Technol 67:2537-2550

110. Segreto T, Teti R, Neugebauer R, Schmidt G (2009) Machinability assessment in turning of NiTi through acceleration sensor monitoring. 2nd Int. Researchers Symp. on IPROMS, Ischia, pp 75-80

111. Vijayaraghavana A, Dornfeld D (2010) Automated energy monitoring of machine tools. CIRP Ann Manuf Technol 59(1):21-24

112. Hayashi M, Yoshioka H, Shinno H (2008) An adaptive control of ultraprecision machining with an in-process micro-sensor. J Adv Mech Des Syst Manuf 2(3):322-331

113. Teti R, Segreto T (2008) Sensor monitoring for cutting process optimisation of low machinability materials. 5th Chemnitz Colloq. on Prod. Techn. CPK, Chemnitz, pp 237-256

114. Kim HY, Ahn JH (2002) Chip disposal state monitoring in drilling using neural network based spindle motor power sensing. Int $\mathrm{J}$ Mach Tools Manuf 42(10):1113-1119

115. Axinte D (2006) Approach into the use of probabilistic neural networks for automated classification of tool malfunctions in broaching. Int J Mach Tools Manuf 46(12-13):1445-1448

116. Haykin S (2008) Neural networks \& learning machines. PrenticeHall, New York

117. Achichea S, Balazinski M, Baron L, Jemielniak K (2002) Tool wear monitoring using genetically-generated, fuzzy knowledge bases. Eng Appl Artif Intell 15:03-314

118. Balazinski M, Jemielniak K (1998) Tool conditions monitoring using fuzzy decision support system, V CIRP International Conference on Monitoring and Automatic Supervision in Manufacturing AC' 98, Miedzeszyn, 115-122

119. Ahn J, Shen Y, Kim H, Jeong H, Cho K (2001) Development of a sensor information integrated expert system for optimizing die polishing. Robot CIM 17(4):269-276

120. Oborski P (2003) Social-technical aspects in modern manufacturing. Int J Adv Manuf Technol 22(Nr 11\&12):848-854

121. Oborski P (2004) Man-machine interactions in advanced manufacturing systems. Int J Adv Manuf Technol 23:227-232

122. Martinsena K, Holtskoga H, Larssona CE (2012) Social aspects of process monitoring in manufacturing systems, 45 th CIRP conference on manufacturing systems. Proced CIRP 3:567-572

123. Oborski P (2013) Integration of process and machine tools monitoring based on advanced information systems, Mechanik, Nr. 8-9, p.411-418/714, ISSN 0025-6552

124. Mourtzis D (2011) Internet based collaboration in the manufacturing supply chain. CIRP J Manuf Sci Technol 4:296-304
125. Wang J, Tse P, He LS, Yeung R (2004) Remote sensing, diagnosis and collaborative maintenance with web-enabled virtual instruments and mini-servers. Int J Adv Manuf Technol 24(9-10): 764-772

126. Jovane F, Koren Y, Boer CR (2003) Present and future of flexible automation: towards new paradigms. Ann CIRP 52(2):543-560

127. Zhou ZD, Chen YP, Fuh JY, Nee AY (2000) Integrated condition monitoring and fault diagnosis for modern manufacturing systems. CIRP Ann 49(1):387-390

128. Vyroubal J (2012) Compensation of machine tool thermal deformation in spindle axis direction based on decomposition method. Precis Eng 36:121-127

129. Jemielniak K (1999) Commercial tool condition monitoring systems. Int J Adv Manuf Technol 15:711-721

130. Szulewski P (2012) Communication methods for data interchange between machine tool control system and monitoring equipment. Inzynieria Maszyn R. 17(z. 2):74-83

131. Carpanzano FJ (2007) Advanced automation solutions for future adaptive factories. Ann CIRP 56(1):435-438

132. Susanu M, Dumur D (2006) Hierarchical predictive control within an open architecture virtual machine tool. CIRP Ann Manuf Technol 55(1):389-392

133. Kistler Company (2012) Measuring and analyzing pressure, force and acceleration. Kistler Company, Winterhur

134. http://www.prometec.de/EN/download_machining.html. Verified: 25.11.2013

135. Kurp T, Gao R, Sah S (2012) Adaptive sensing for energy-efficient manufacturing system and process monitoring. CIRP J Manuf Sci Technol 5(4):328-336

136. Vellekoop JM, Jakoby B, Chabicovsky R (2003) Development trends in the field of sensors. e\&i Elektrotechnik und Informationstechnik 120(11):388-394

137. Shams S, Lee JY, Han C (2012) Compact and lightweight optical torque sensor for robots with increased range. Sensors Actuators A 173:81-89

138. ZuDe Z, Quan L, QingSong A, Cheng X (2011) Intelligent monitoring and diagnosis for modern mechanical equipment based on the integration of embedded technology and FBGS technology. Measurement 44:1499-1511

139. Martin J (2010) Commercial MEMS case studies: market drivers, designs, materials and processes. Int J Adv Eng Sci Appl Math 2(12):23-27

140. Pryputniewicz RJ (2012) Current trends and future directions in MEMS. Exp Mech 52:289-303

141. Zhang Y, Gu Y, Vlatkovic V, Wang X (2004) Progress of smart sensor and smart sensor networks, IEEE Publications, 3600-3606

142. Mekid S, Pruschek P, Hernandez J (2009) Beyond intelligent manufacturing: a new generation of flexible intelligent NC machines. Mech Mach Theory 44:466-476

143. Lange D (2004) Systems and strategies for control-systemintegrated process and machine condition monitoring. CIRP International Conference on High Performance Cutting, Aachen

144. Ferraz F, Coelho RT (2005) Data acquisition and monitoring in machine tools with $\mathrm{CNC}$ of open architecture using internet. Adv Manuf Technol 26:90-97

145. Cheng $T$ (2003) Intelligent machine tools in a distributed network manufacturing mode environment. Int Adv Manuf Technol 17(3): 221-232

146. Pritschow G, Kramer C (2005) Open system architecture for drives. CIRP Ann Manuf Technol 54(1):375-378

147. Desforges X, Archimede B (2006) Multi-agent framework based on smart sensors/actuators for machine tools control and monitoring. Eng Appl Artif Intell 19(6):641-655

148. Morales-Velazquez L, Romero-Troncoso RJ et al (2010) Openarchitecture system based on a reconfigurable hardware-software multi-agent platform for CNC machines. J Syst Archit 56:407-418 
149. Laplante PA (2004) Real-time systems design and analysis. Wiley, New York

150. Ceden W, Laplante PA (2007) An overview of real-time operating systems. Technol Rev JALA 12:40-45

151. Kopetz H (2011) Real-time systems, design principles for distributed embedded applications, 2nd edn. Springer, New York

152. Kleinjohann B (2004) Design methods and applications for distributed embedded systems. Springer, New York

153. Long YH, Zhou ZD et al (2009) Embedded-based modular NC systems. Int J Adv Manuf Technol 40:749-759

154. Lampka K, Perathoner S, Thiele L (2010) Analytic real-time analysis and timed automata: a hybrid methodology for the performance analysis of embedded real-time systems. Des Autom Embed Syst 14:193-227

155. Pereira CE, Carro L (2007) Distributed real-time embedded systems: recent advances, future trends and their impact on manufacturing plant control. Annu Rev Control 31:81-92

156. Vijayaraghavan A, Sobel W, Fox A, Dornfeld D, Warndorf P (2008) Improving machine tool interoperability using standardized interface protocols: MTConnect. Int. Symposium on Flexible Automation, ASME, Atlanta, pp 23-26

157. Campos JG, Miguez LR (2011) Standard process monitoring and traceability programming in collaborative $\mathrm{CAD} / \mathrm{CAM} / \mathrm{CNC}$ manuf. scenarios. Comput Ind 62(I 3):311-322

158. Ridwan F, Xu X (2013) Advanced CNC system with in-process feed-rate optimisation. Robot Comput Integr Manuf 29(3):12-20

159. Erl T, Puttini R, Mahmood Z (2013) Cloud computing: concepts, technology \& architecture. Prentice Hall, New York

160. Mell P, Grance T (2011) The NIST definition of cloud computing, National Institute of Standards and Technology, U.S. Department of Commerce

161. Zhang L., Luo Y., Tao F., Li B.H., Ren L., Zhang X (2012) Cloud manufacturing: a new manufacturing paradigm, Enterprise Information Systems, 1-21

162. Xu X (2011) From cloud computing to cloud manufacturing. Robot Comput Integr Manuf Syst. doi:10.1016/j.rcim.2011.07.002

163. Wang L (2013) Machine availability monitoring and machining process planning towards Cloud manufacturing. CIRP J Manuf SciTechn 6(4):263-273

164. Nagorny K, Colombo AW, Schmidtmann U (2012) A service- and multi-agent-oriented manufacturing automation architecture An IEC 62264 level 2 compliant implementation. Comput Ind 63: 813-823

165. Robert J. Benjamin, J (1992) Blunt, critical IT issues: the next ten years. Sloan Manag Rev, 7-19

166. Dewire DT (1994) Client/server computing. McGraw-Hill, New York

167. Boar BH (1994) Implementing client/server computing. McGrawHill, New York

168. Bongaerts L, Monostori L, McFarlane D, Kadar B (1998) Hierarchy in distributed shop flor control. Proc of the First Intern Workshop on Intelligent Manuf. Systems, Lausanne, pp 97-113

169. Laplante PA, Ovaska SJ (2011) Real-time systems design and analysis: tools for the practitioner. Wiley, New York

170. Boyer SA (2010) SCADA: supervisory control and data acquisition, 4th edition, ISA International Society of Automation

171. Barana O, Barbato P et al (2010) Comparison between commercial and open-source SCADA packages - a case study. Fusion Eng Des $85: 491-495$

172. Nguyen H, Rivas R, Nahrstedt K (2011) iDSRT: integrated dynamic soft real-time architecture for critical infrastructure data delivery over WLAN. Mob Netw Appl 16:96-108

173. Nicholson A et al (2012) SCADA security in the light of cyberwarfare. Comput Secur 31:418-436

174. Brandl D, Owen P (2001) A tutorial on the ANSI/ISA95 Enterprise/ Control BR\&L Consulting. www.brlconsulting.com/.../2003-09\%
20IEE\%20, Dennis Brandl Peter Owen. BR\&L Consulting Eli Lilly\&Co

175. Ryu DH, Kim HJ, Um K (2009) Reducing security vulnerabilities for critical infrastructure. J Loss Prev Process Ind 22:1020 1024

176. Karnouskos S, Colombo AW (2011) Architecting the next generation of service-based SCADA/DCS system of systems. Proc. of the 37th IEEE Annual Conf. on Industrial Electronics (IECON '11), Melbourne

177. Sen S (1997) Multiagent systems: milestones and new horizons. Trends Cogn Sci 1(9):334-340

178. Oborski P (2010) Multiagent shop floor control. Adv Manuf Sci Technol 34(3):61-72

179. Tatara A, Cinar A, Seymour F (2007) Control of complex distributed systems with distributed intelligent agents. J Process Control $17: 415-427$

180. Monostori L, Vancza J, Kumara SRT (2006) Agent-based systems for manufacturing. Ann CIRP 55(2):697-720

181. Garcia-Fornes A, Hubner JF (2011) Infrastructures and tools for multiagent systems for the new generation of distributed systems. Eng App Artif Intel 24:1095-1097

182. Molina A, Rodriguez CA et al (2005) Next-generation manufacturing systems: key research issues in developing and integrating reconfigurable and intelligent machines. Int J Comput Integr Manuf 18(7):525-536

183. Lim MK, Zhang DZ (2004) An integrated agent-based approach for responsive control of manufacturing resources. Comput Ind Eng 46: 221-232

184. Marik V, McFarlane D (2005) Industrial adoption of agent-based technologies. IEEE Intell Syst 20(1):27-35

185. Shen W, Hao Q, Yoon HJ, Norrie DH (2006) Applications of agentbased systems in intelligent manufacturing: an updated review. Adv Eng Inform 20:415-431

186. Leitao P (2009) Agent-based distributed manufacturing control: a state-of-the-art survey. Eng Appl Artif Intell 22:979-991

187. Wang LC, Lin SK (2009) A multi-agent based agile manufacturing planning and control system. Comput Ind Eng 57:620-640

188. Barbati M, Bruno G, Genovese A (2012) Applications of agentbased models for optimization problems: a literature review. Expert Syst Appl 39:6020-6028

189. Vitabile S, Conti V, Militello C, Sorbello F (2009) An extended JADE-S based framework for developing secure multi-agent systems. Comput Stand Interfaces 31:913-930

190. FIPA (www.fipa.org/)

191. Lee J, Ni J et al (2006) Intelligent prognostics tools and emaintenance. Comput Ind 57(6):476-489

192. Chen KY, Chen CJ (2010) Applying multi-agent technique in multisection flexible manufacturing system. Expert Syst Appl 37: 7310-7318

193. Mangina E, McArthur S, McDonald J (2000) Autonomous agents for distributed problem solving in condition monitoring. Lect Notes Comput Sci, 683-692

194. Collis J, Ndumu D (1999) The Zeus agent building toolkit-ZEUS Technical Manual, British Telecommunication

195. Mangina E, McArthur S, McDonald J, Moyes A (2001) A multi agent system for monitoring industrial gas turbine start-up sequences. IEEE Trans Power Syst 16:396-401

196. McArthur SD, Strachan SM, Jahn G (2004) The design of a multiagent transformer condition monitoring system. IEEE Trans Power Syst 19(4):1845-1852

197. Sayed MS, Lohse N (2013) Distributed Bayesian diagnosis for modular assembly systems - a case study. J Manuf Syst 32:480 488

198. Ribeiro L et al (2010) An agent-based interaction-oriented shop floor to support emergent diagnosis. IEEE International Conference on Industrial Informatics, Osaka 